UCRL-ID-126013

\title{
Comparison of ARAC Calculations with Surface and Airborne Measurements for the ACE Field Trials
}

Kevin T. Foster

Brenda Pobanz

November 1996

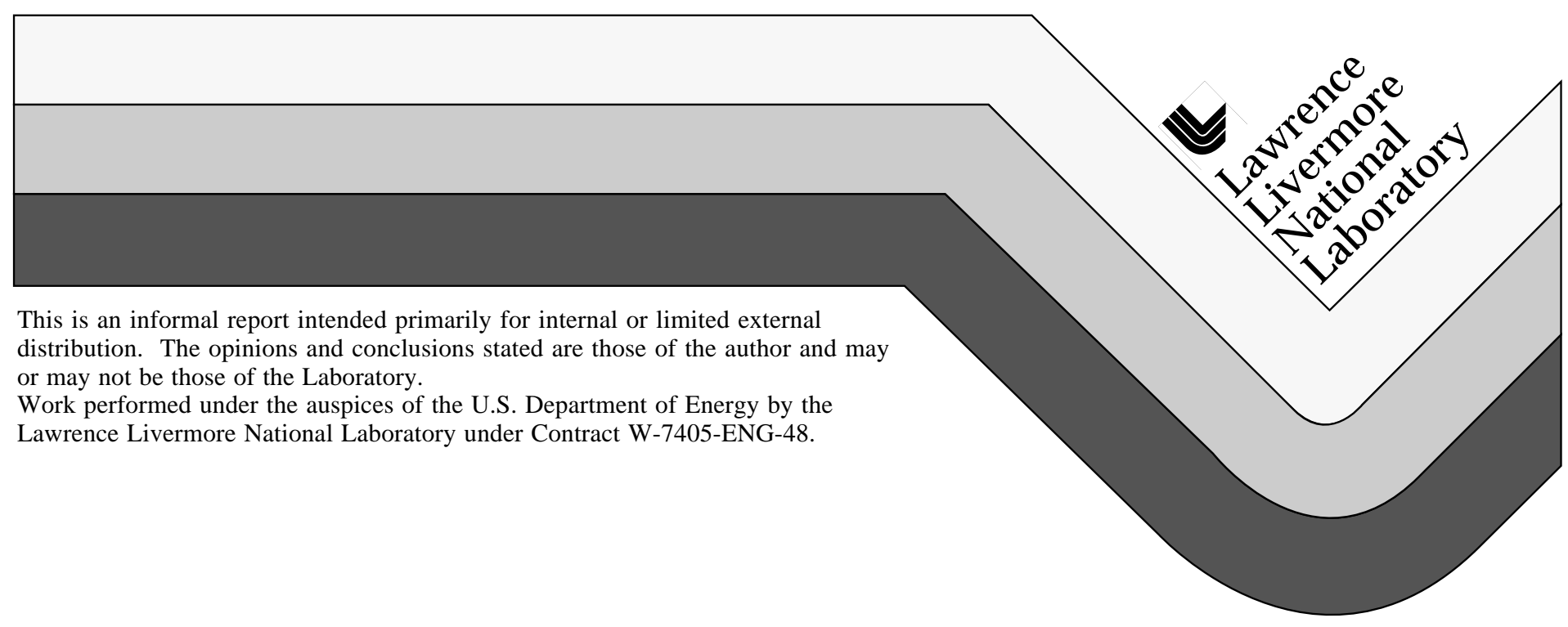




\section{DISCLAIMER}

This document was prepared as an account of work sponsored by an agency of the United States Government. Neither the United States Government nor the University of California nor any of their employees, makes any warranty, express or implied, or assumes any legal liability or responsibility for the accuracy, completeness, or usefulness of any information, apparatus, product, or process disclosed, or represents that its use would not infringe privately owned rights. Reference herein to any specific commercial product, process, or service by trade name, trademark, manufacturer, or otherwise, does not necessarily constitute or imply its endorsement, recommendation, or favoring by the United States Government or the University of California. The views and opinions of authors expressed herein do not necessarily state or reflect those of the United States Government or the University of California, and shall not be used for advertising or product endorsement purposes.

This report has been reproduced directly from the best available copy.

Available to DOE and DOE contractors from the Office of Scientific and Technical Information

P.O. Box 62, Oak Ridge, TN 37831

Prices available from (615) 576-8401, FTS 626-8401

Available to the public from the

National Technical Information Service

U.S. Department of Commerce 5285 Port Royal Rd.,

Springfield, VA 22161 


\title{
Comparison of ARAC Calculations with Surface and Airborne Measurements for the ACE Field Trials
}

\author{
Kevin T. Foster and Brenda M. Pobanz
}

Atmospheric Science Division, Lawrence Livermore National Laboratory

\begin{abstract}
Schalk (1996) gives a detailed discussion of the Atmospheric Release Advisory Capability's (ARAC) core atmospheric transport and diffusion models, CG-MATHEW and ADPIC, and their application to the fourth in a series of five Atmospheric Collection Equipment (ACE) field tracer releases. These ACE trials were sponsored by the Air Force Technical Applications Center (AFTAC) for the purpose of investigating specific tracer monitoring methods and equipment (Corey, 1994). Three different tracers (sulfur hexaflouride and two particulate tracers) were released simultaneously for each experiment. This document extends the discussion found in Schalk (1996) by providing a brief summary of the sulfur hexaflouride (SF6) modeling results for three of the remaining four ACE trials (the tracer plume from the fifth trial was not located by the monitoring teams and provided no tracer measurements for model comparison). This summary is followed by a discussion of model results for the two particulate tracers which were co-released with SF6.

Table 1 lists the four ACE releases for which ARAC model calculations have been generated. For a detailed description of the modeling methodology, general experiment parameters, and detailed comparison results for the SF6 tracer dispersed in release number four, the reader is referred to Schalk (1996). The following discussion first summarizes SF6 results corresponding to releases one through three by presenting depictions of the pertinent modeled surface and upper level wind patterns, contoured SF6 concentrations, and a discussion of the comparison between modeled and measured minimum SF6
\end{abstract}

detectable concentrations (10 ppt) for each of the three experiments.

Table 1 ACE Tracer Releases Modeled by ARAC

\begin{tabular}{ccr} 
Release & Date & Release Time \\
\hline 1 & 20 OCT 93 & 1600-1930 UTC \\
2 & 25 OCT 93 & $1245-1545$ UTC \\
3 & 29 OCT 93 & $1400-1700$ UTC \\
4 & 03 NOV 93 & $1315-1615$ UTC \\
\hline
\end{tabular}

\section{$\underline{\text { SF6 Release } 1}$}

As was done for all of the modeled releases, available surface and upper level wind data were interpolated to 15-minute averaged, three-dimensional, massconsistent gridded wind fields. These wind fields were then used in the ADPIC particle dispersion model. Selected near-surface modeled wind fields and associated contoured plume concentration patterns (representing calculated instantaneous positions of the SF6 cloud) are shown in Figures 1-10 for various times during the tracer transport for the first experiment. The surface wind conditions were modeled to have a strong influence within the lower portion of the boundary layer, and therefore modeled winds at the expected SF6 transport layers did not significantly differ from those depicted in these Figures. For simplicity, the plume concentration contours are shown only for 1.5 meter height above the surface. These are included to aid in the visualization of plume movement and dimensions. However, the reader should note that the process of 
atmospheric diffusion and transport can produce varying pattern size, shape, and location at different altitudes.

\section{Modeled Wind Flow Pattern}

Wind conditions across the Snake River Plains at the release time (1600 UTC) were generally light and variable, with a slight down-valley (northeast to southwest) flow (Figure 1). The tracer was initially released (at coordinates 343.3 East and 4828.4 North) into these conditions with the first hour of transport (1600-1700 UTC) moving the tracer slowly to the southwest, parallel to Big Lost River (Figure 2).

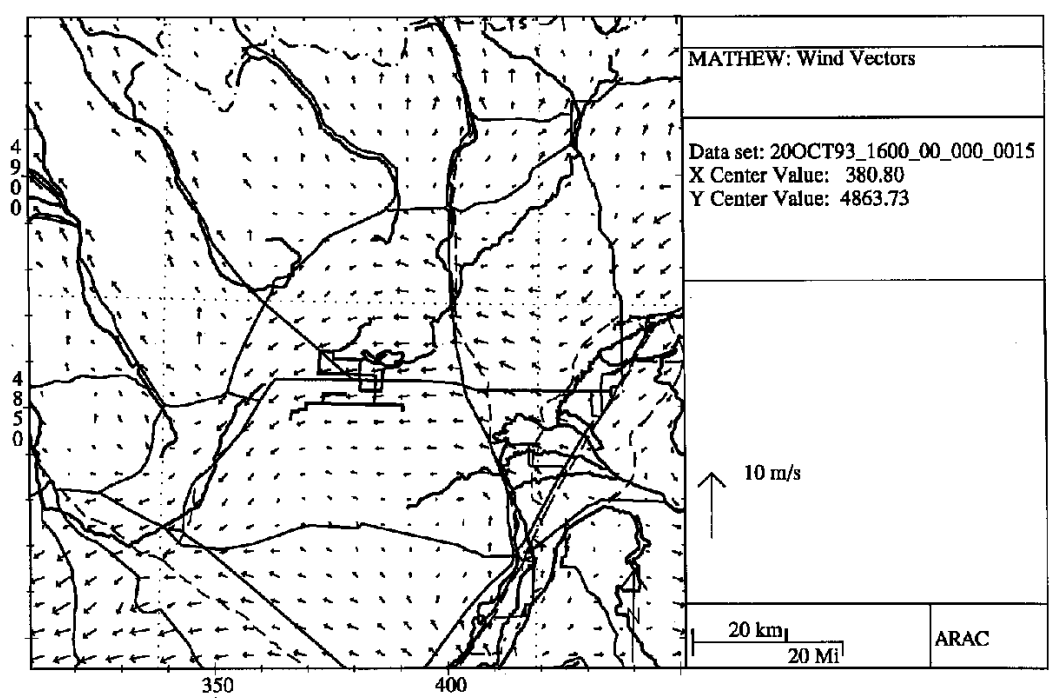

Figure 1. Modeled near-surface wind field for Release \#1 at 1600 UTC. The arrows point in the direction the wind is blowing. Their length is proportional to the wind speed. The axis labels are in local Universal Transverse Mercator coordinates.

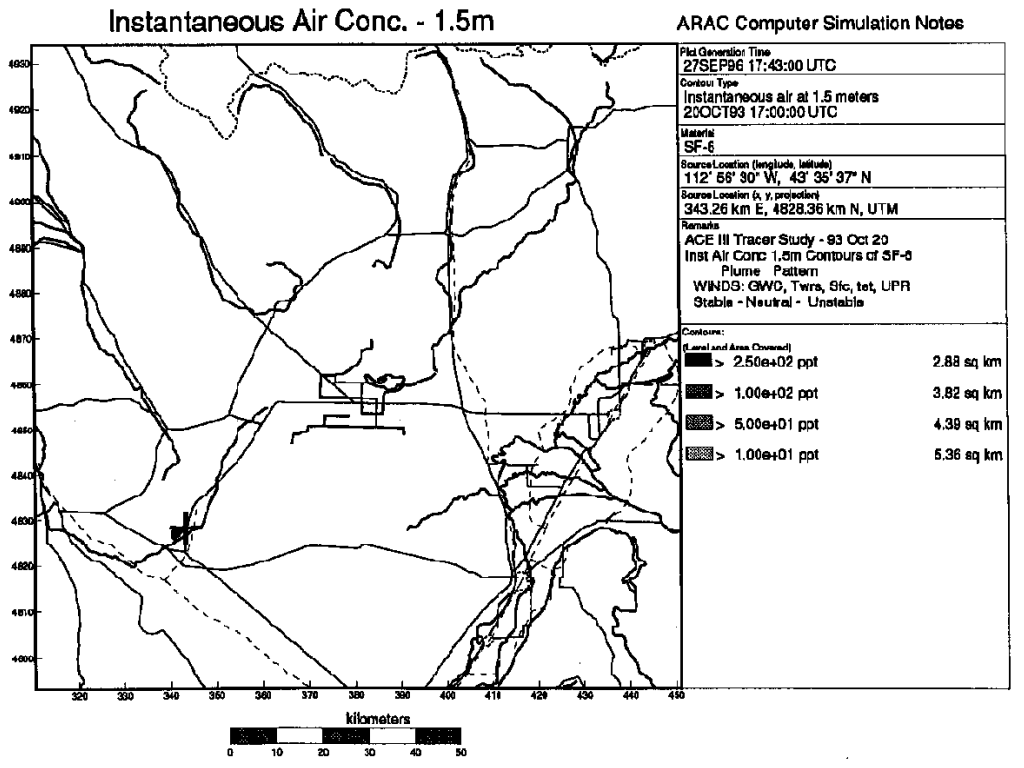

Figure 2. Modeled SF6 surface air concentrations (in ppt) for Release \#1 at 1700 UTC. Outer contour illustrates the predicted $10 \mathrm{ppt}$ measurement threshold concentration pattern. The axis labels are in local Universal Transverse Mercator coordinates. "+" indicates the SF6 release location. 
By 1700 UTC a general flow reversal had begun across the Plains (Figure 3) with the tracer still under very light wind conditions, but now moving almost due north. Over the next two hours (1700-1900 UTC) stronger, consistent southwest winds became well-established over the Plains (Figure 4). During this time period the modeled plume moved to the northnortheast directly over a portion of the Big Lost River (Figure 5). This wind pattern remained consistent until about 2200 UTC when a change in the up-valley flow at the mouth of the canyons in the northern portion of the modeled area showed hints of reversal, setting up an area of convergence and light surface winds (illustrated by very short arrows in Figure 6) in the region north of Mud Lake, at about Universal Transverse Mercator (UTM) coordinates 380 East, 4880 North. The horizontal movement of the plume then tended to be forced primarily to the north-northeast (Figure 7).

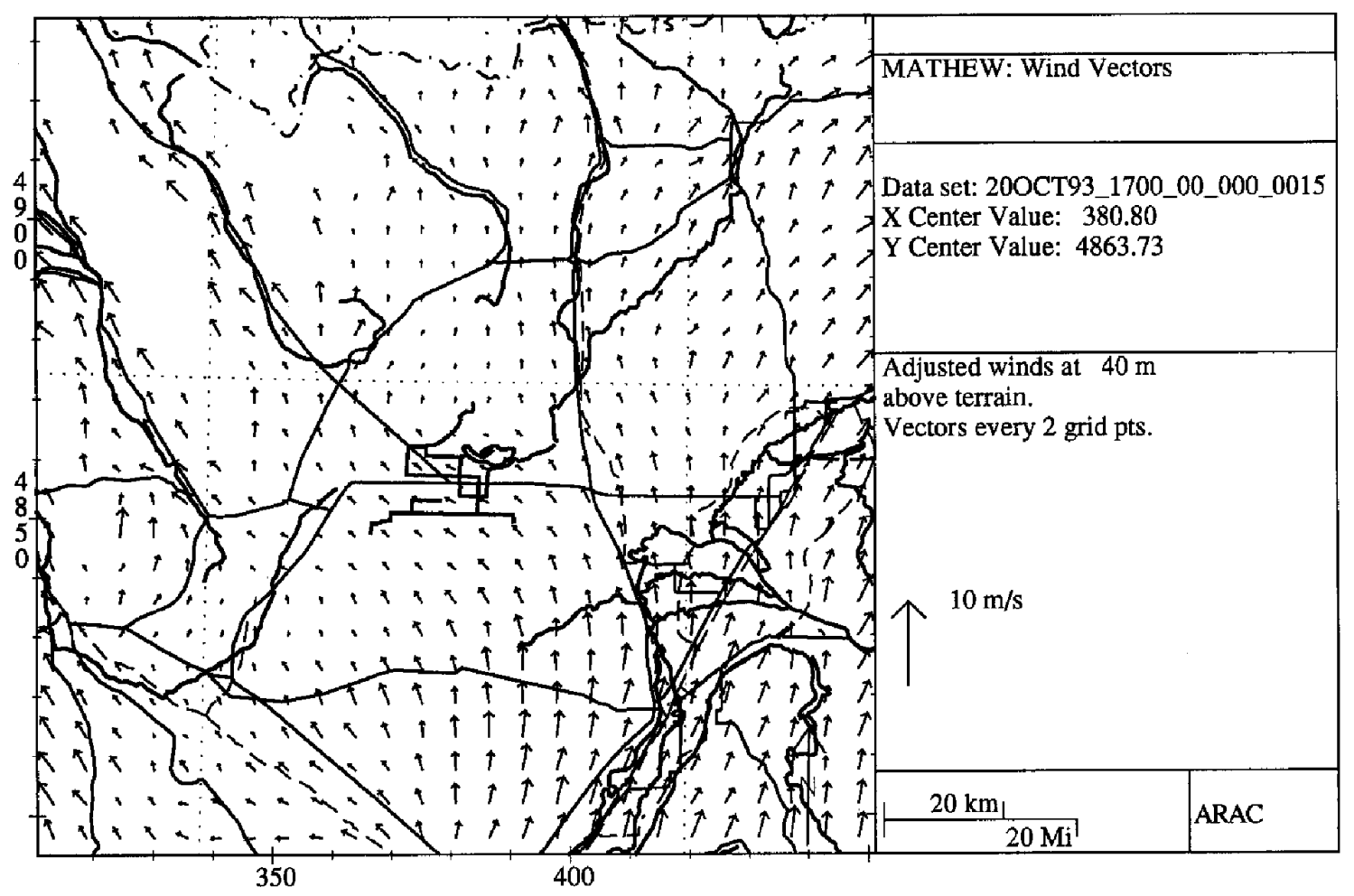

Figure 3. Modeled near-surface wind field for Release \#1 at 1700 UTC. 


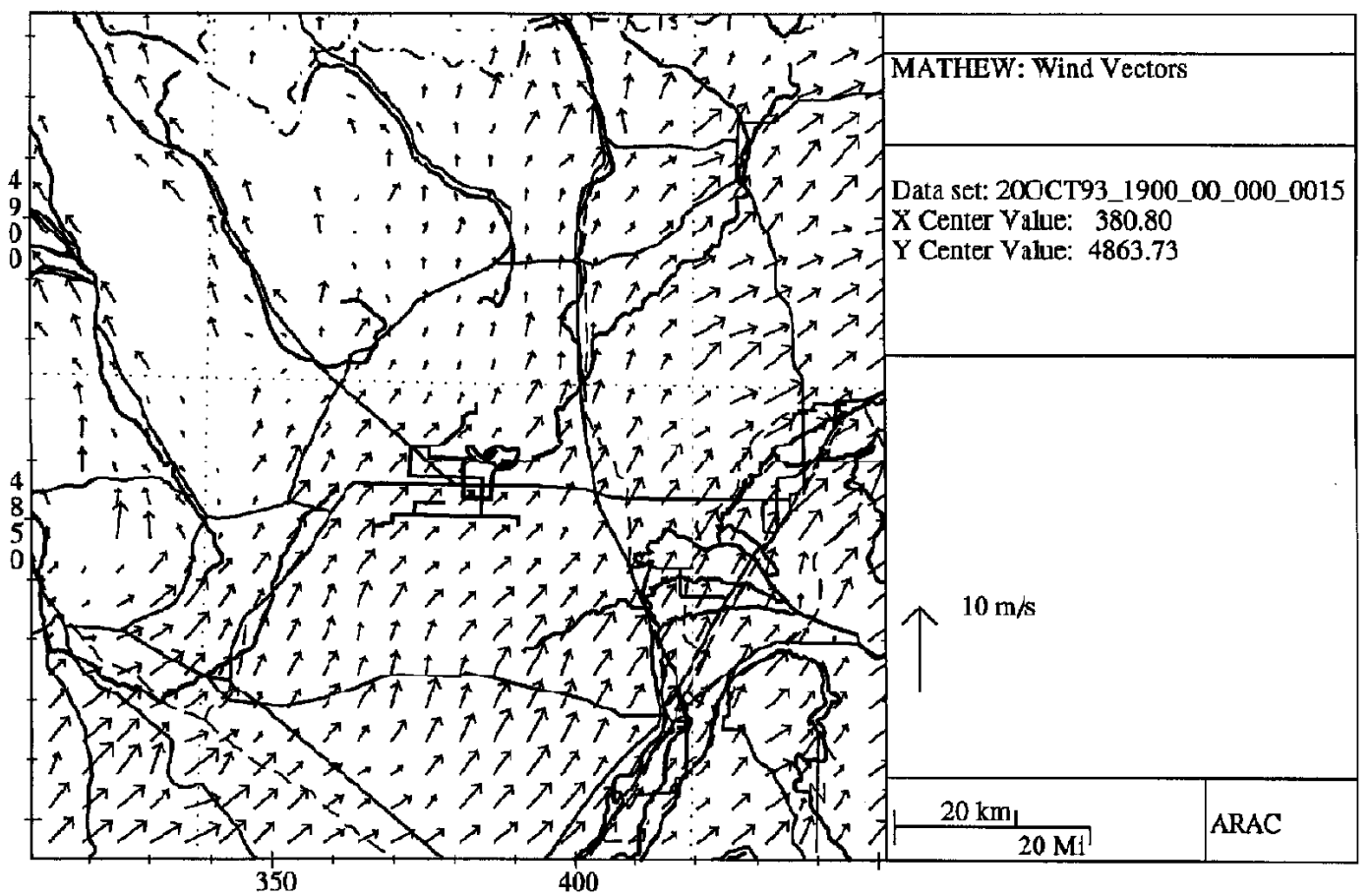

Figure 4. Modeled near-surface wind field for Release \#1 at 1900 UTC.

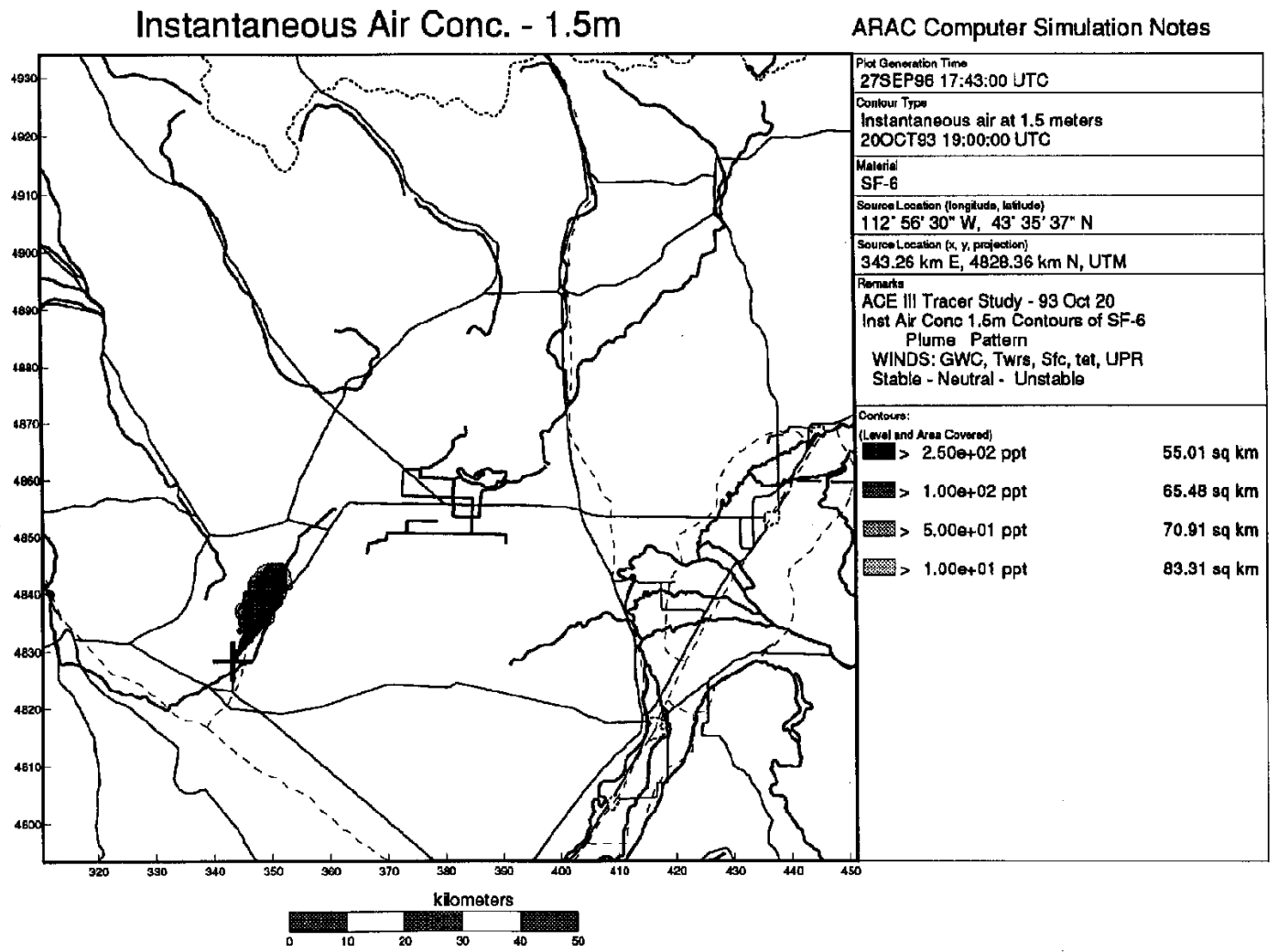

Figure 5. Modeled SF6 surface air concentrations (in ppt) for Release \#1 at 1900 UTC. 


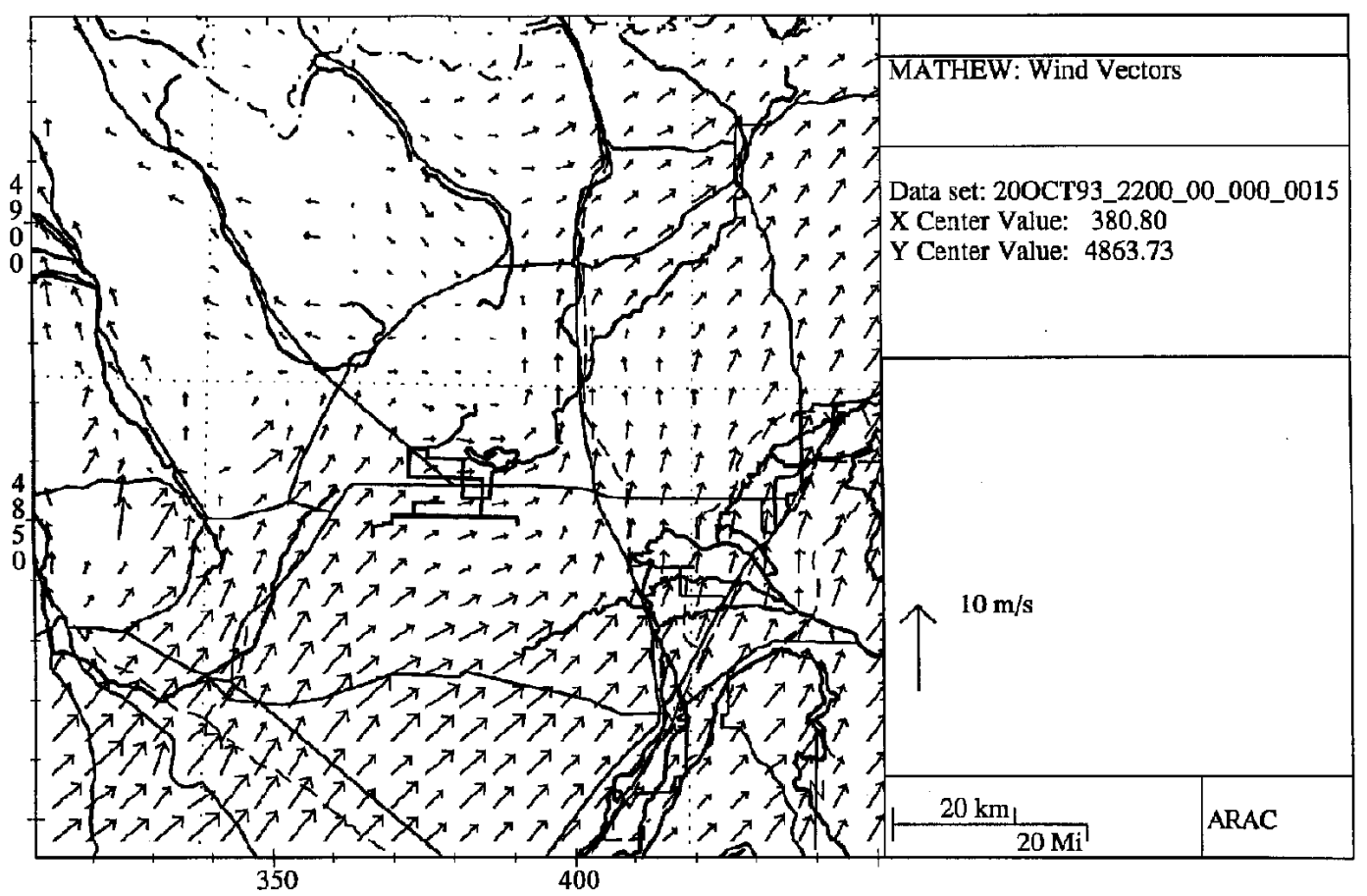

Figure 6. Modeled near-surface wind field for Release \#1 at 2200 UTC.

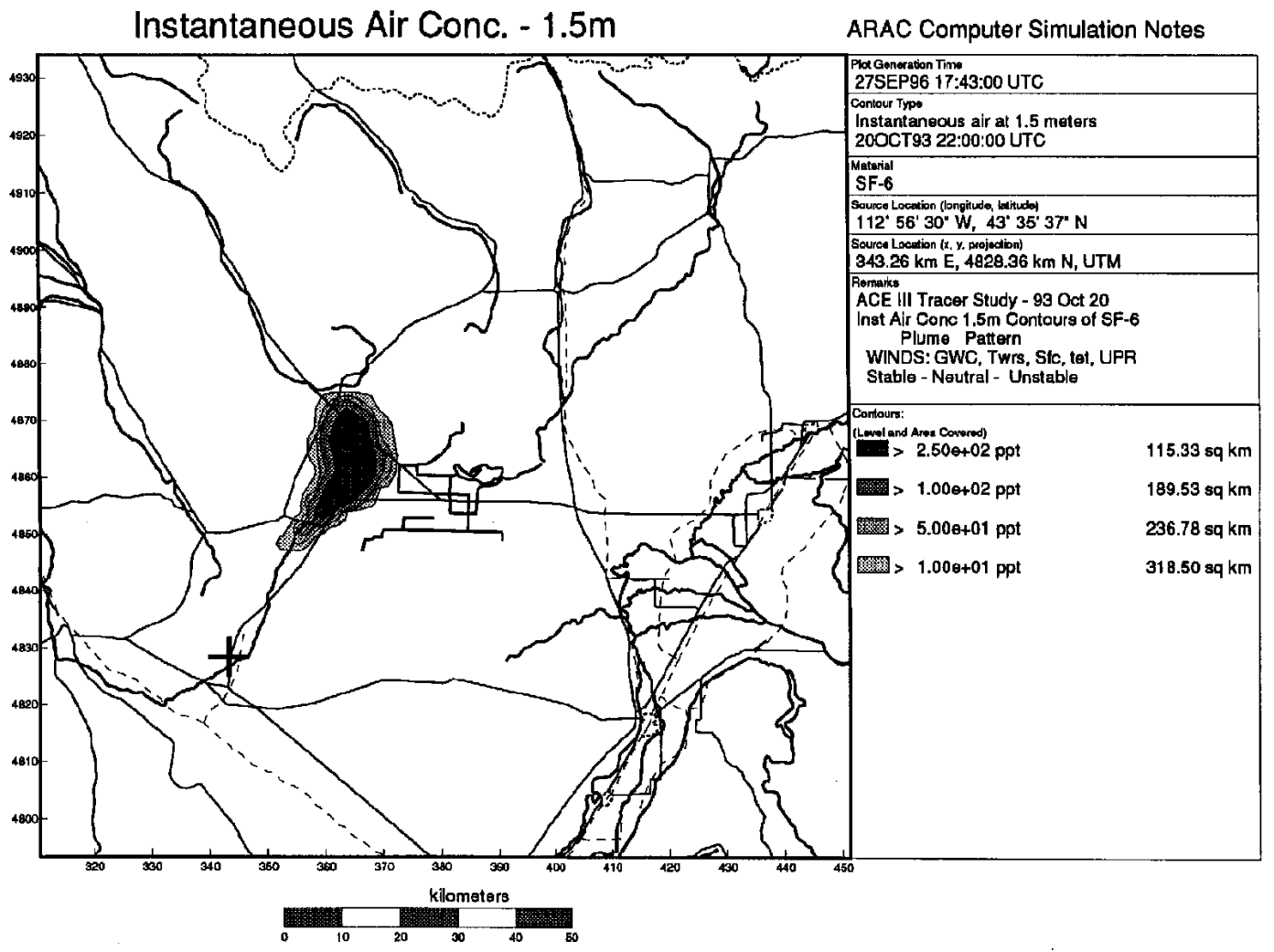

Figure 7. Modeled SF6 surface air concentrations (in ppt) for Release \#1 at 2200 UTC. 
Figures 8 and 9 show that this flow reversal continued and spread to the entire northern half of the modeled domain as the afternoon progressed. As this occurred, the area of convergence between the northnortheast winds and the south-southwest winds moved slowly to the south. The remainder of the calculation shows no major change in the plume position, with only very slow movement of the plume back onto itself (to the southwest) as it progresses along with the advancing area of northeast winds (Figure 10).

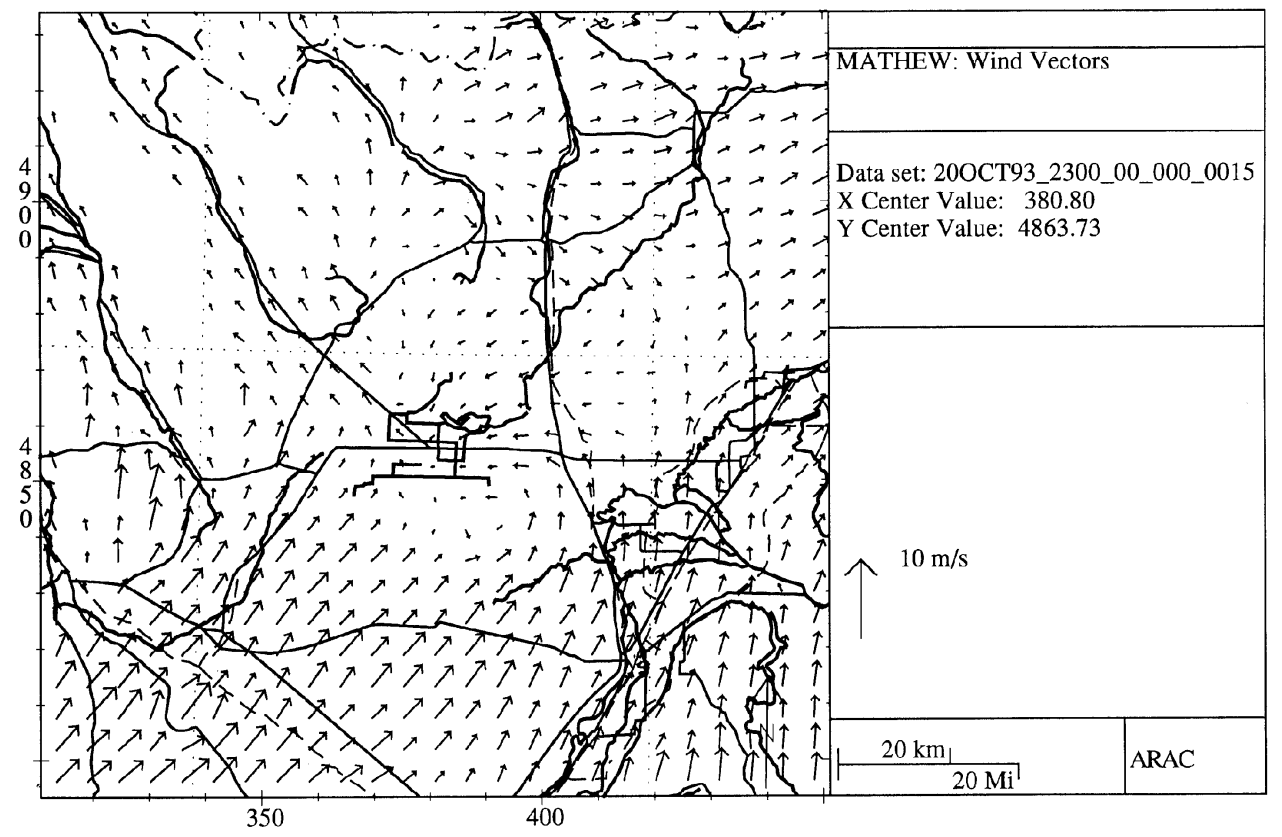

Figure 8. Modeled near-surface wind field for Release \#1 at 2300 UTC.

\section{Surface Measurement Comparison}

Measurements of the SF6 cloud are available both at the surface, from a truckmounted collector, and at several levels above the surface from an airplane sampler. These measurements are presented in Figures 11 through 13 as cloud "hits" (e.g. the measured concentration is at least 10 ppt) or "misses" (e.g. the concentration is less than $10 \mathrm{ppt}$ ). A subjective comparison between the modeled $10 \mathrm{ppt}$ surface concentration contours generated every 15 minutes during the measurement period (similar to those shown in the earlier
Figures) and the truck data shown in Figure 11 was completed. Truck data were extracted from the log manuscript given in Appendix F of Corey (1994). Although the concentration contour patterns in the earlier Figures may be used to estimate plume movement by the reader, the reader is cautioned that a full time series has not been included. Direct comparison of model results and many of the measurements using these figures alone is hindered by the difference between measurement and calculated plume pattern times. 


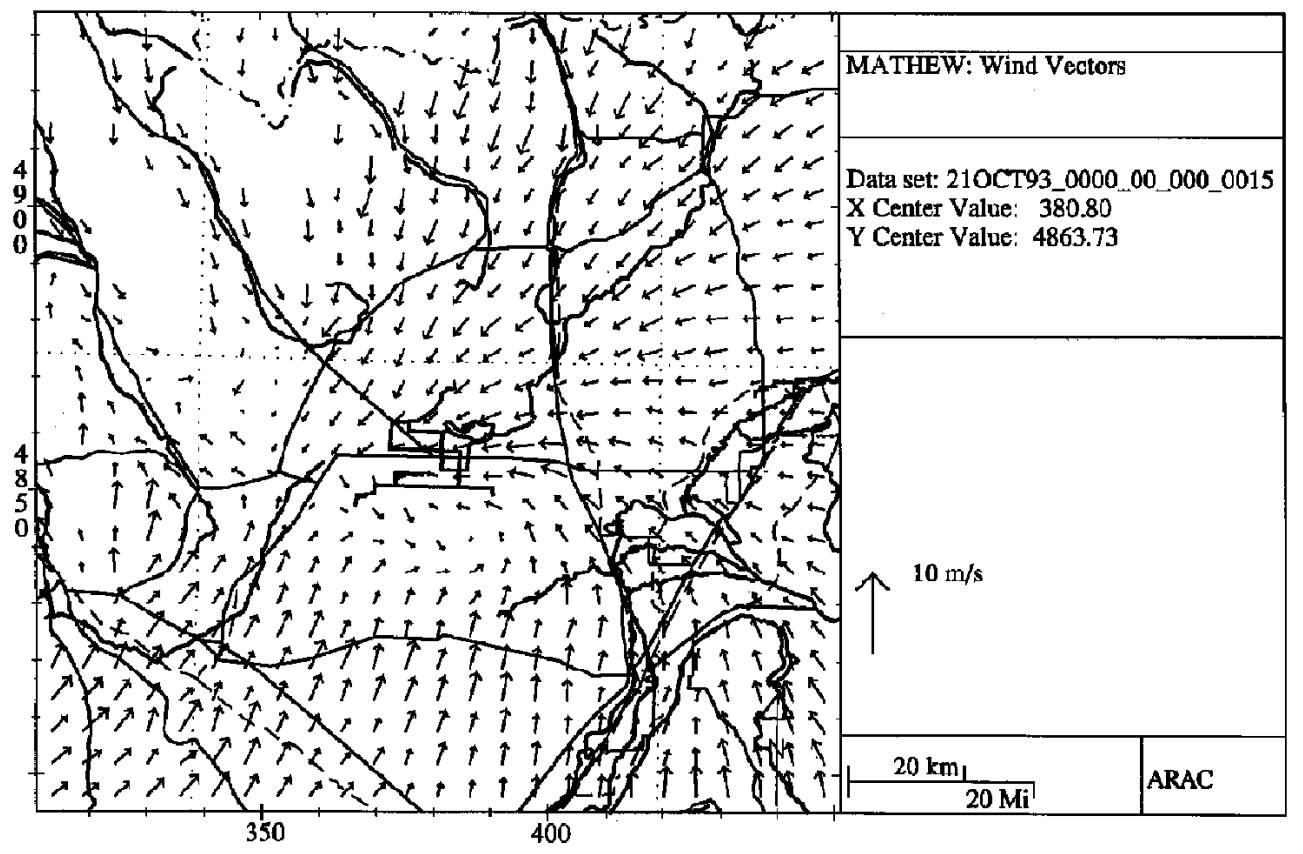

Figure 9. Modeled near-surface wind field for Release \#1 at 0000 UTC.

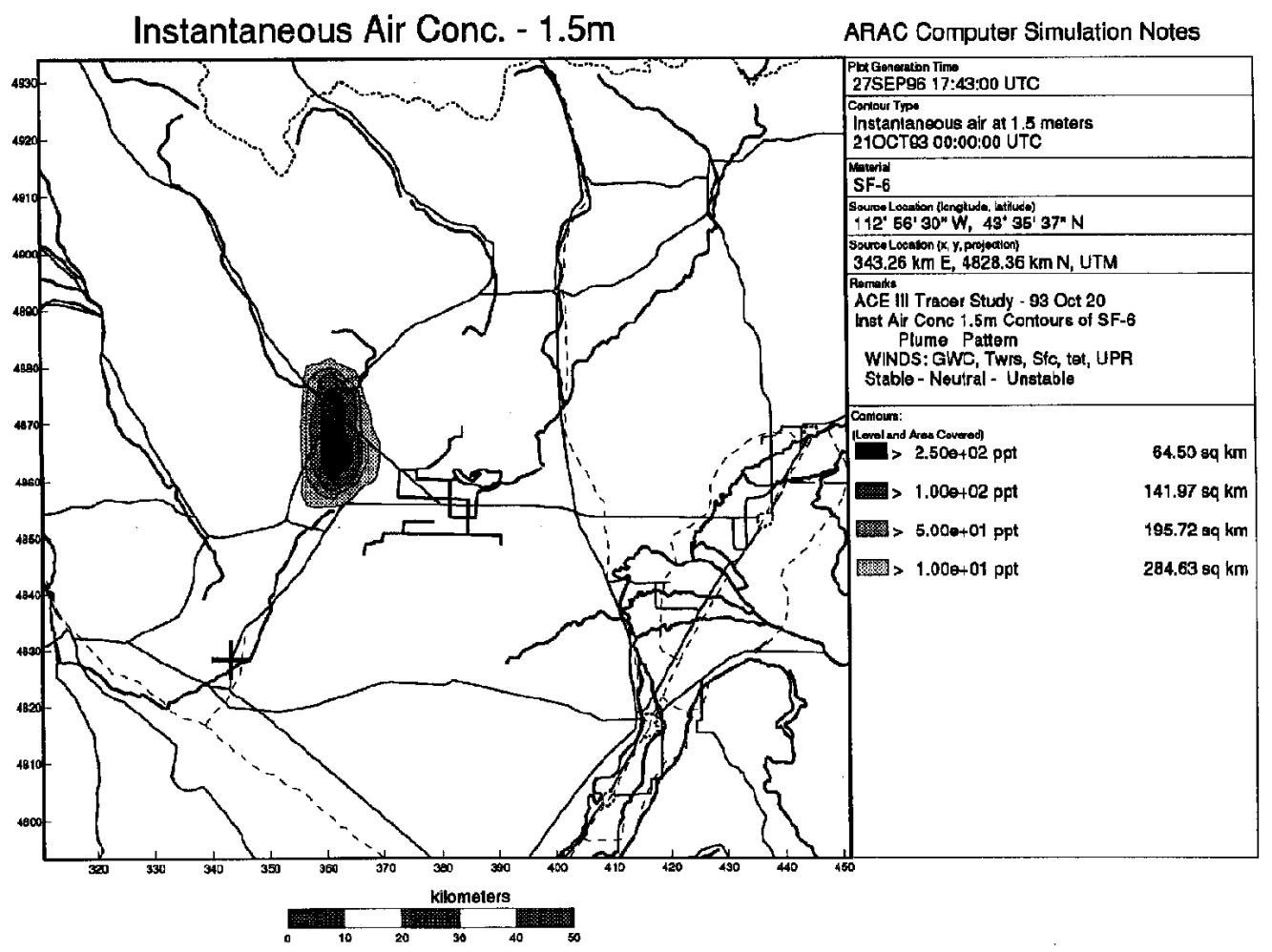

Figure 10. Modeled SF6 surface air concentrations (in ppt) for Release \#1 at 0000 UTC. 


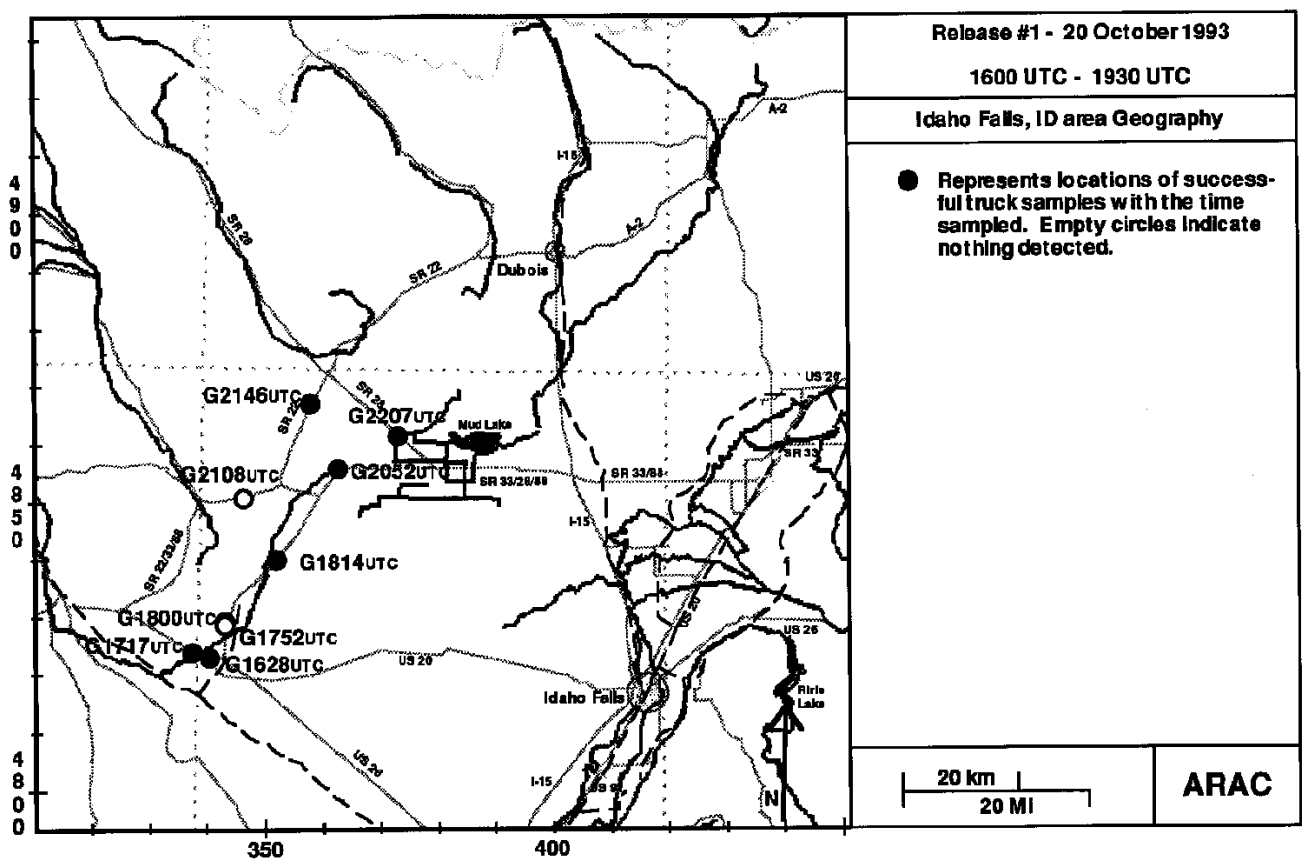

Figure 11. SF6 surface measurements for Release \#1. Solid circles indicate locations of plume "hits" (e.g. measurement of at least 10 ppt). Empty circles indicate locations of plume "misses" (e.g. measurement less than $10 \mathrm{ppt}$ ). The times of the measurements are indicated for each location.

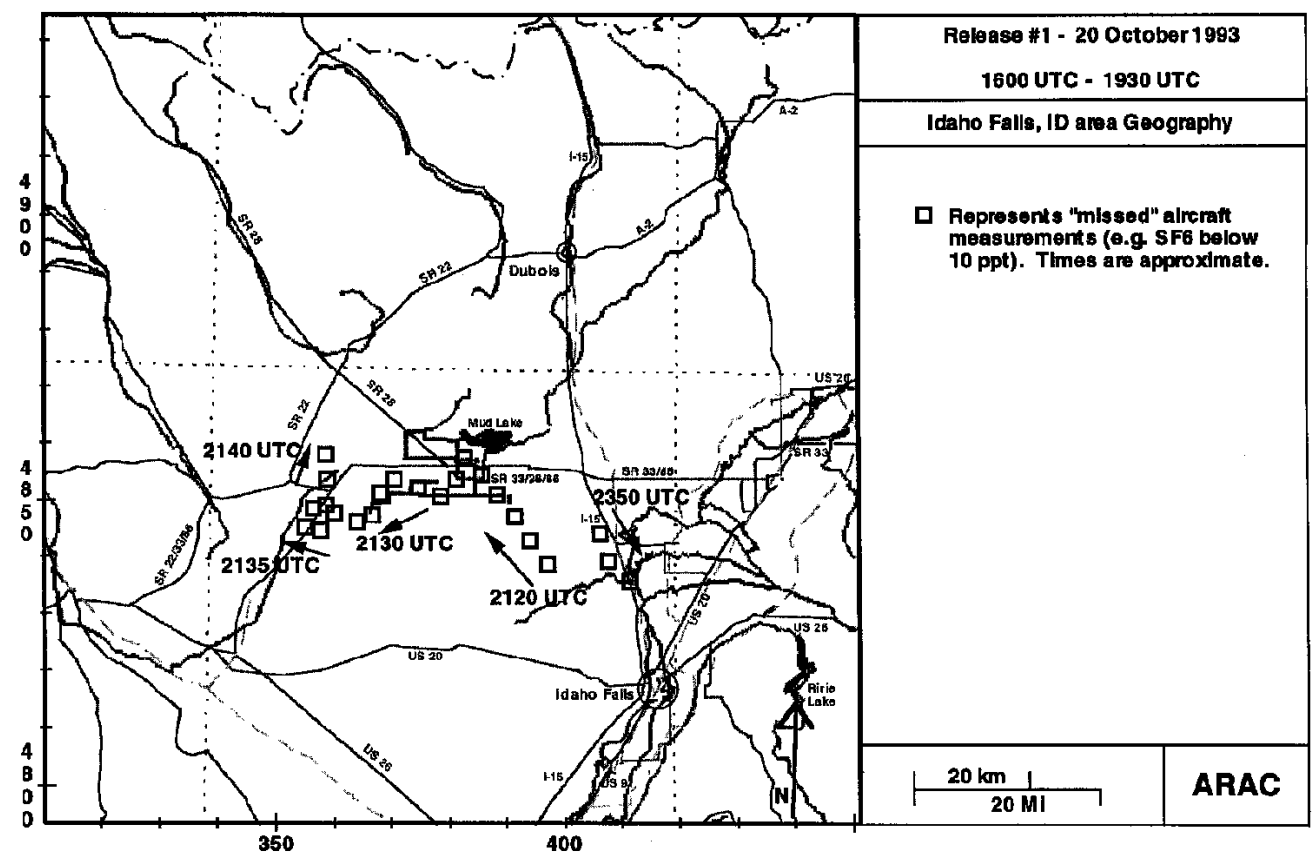

Figure 12. SF6 aircraft plume "misses" (measurements less than $10 \mathrm{ppt)}$ for Release \#1. The approximate times of the measurements are indicated. 
The comparison (using the full plot series) did yield relatively good agreement. The first two truck measurement hits (at 1628 and 1717 UTC) to the southwest of the release point however are not reproduced by the model. Although the modeled plume moves toward the measurement points, it does not reach the truck locations. At 1800 UTC the modeled plume boundary falls very close to the 1752 and 1800 UTC measurements, confirming the plausibility of the measurement miss and hit from nearly identical positions. The modeled plume again falls short of the 1814 UTC measurement, progressing only about half the distance needed to the north-northeast to reach the truck location. By 2100 UTC however the modeled plume covers the 2052 UTC sampling location and also missed the 2108 UTC truck location, agreeing with both measurements. Calculations also show the plume covering the 2146 UTC truck location, and place the plume boundary at the 2207 UTC measurement. Of the nine measurement points, the calculations do not reproduce 3 of the measurements, but agree well with the remaining 6 points.

\section{Airborne Measurement Comparison}

A similar comparison between model calculations and the aircraft measurement data was completed. Because the aircraft flew at several altitudes during the measurement period, comparison of the aircraft data with model calculations is not as straightforward. Contour patterns at several altitudes were generated for the comparison. It is clear from this comparison that the model agrees with the measurement misses shown in Figure 12, with the aircraft skirting the southern and southwestern modeled plume boundary from about 2130 to 2140 UTC. Figure 13 shows the aircraft measurement hits. These measurements were taken over an approximately two hour period. In comparing these data with the modeled plume (at the appropriate time and altitude) we can make a general statement that the calculations agree with the data taken when the aircraft UTM coordinate location was between about 360 and 380 East, and between about 4860 and 4875 North (illustrated as region A in Figure 13).

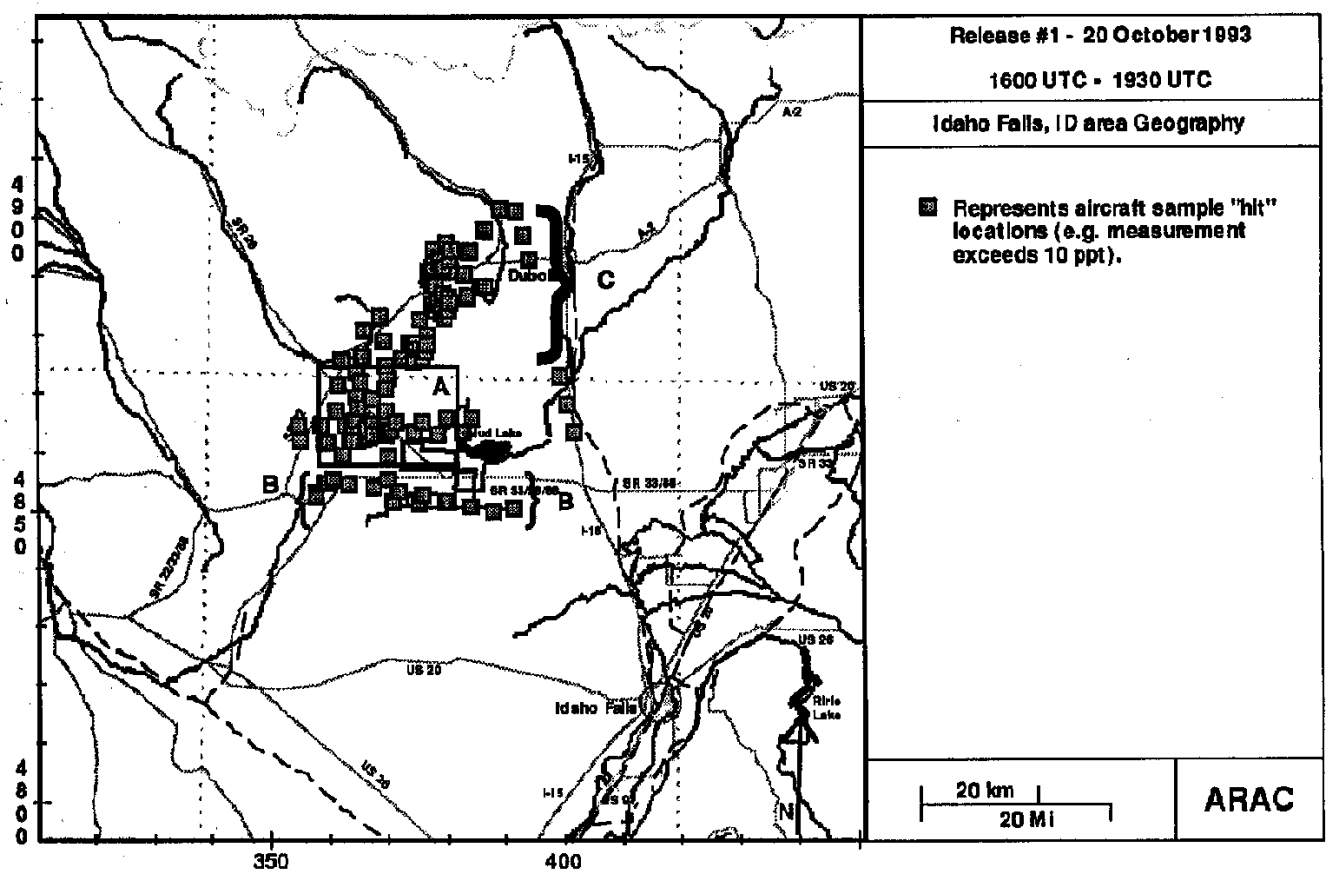

Figure 13. SF6 aircraft plume "hits" (measurements of at least $10 \mathrm{ppt}$ ) for Release \#1. 
The modeled 10 ppt contour did not usually reach the other locations. Two regions of disagreement between the data and calculations are illustrated in Figure 13 (labeled B and C). Sampling in region B was conducted between about 2220 and 2235 UTC. By this time the modeled plume had moved just slightly beyond (to the north) of this area. Region $\mathrm{C}$ was sampled after about 2250 UTC. This was in the location and time period of the wind convergence mentioned earlier which prevented the modeled plume from moving any more to the northeast. Therefore the modeled plume never entered region $\mathrm{C}$.

\section{$\underline{\text { SF6 Release } 2}$}

\section{Modeled Wind Flow Pattern}

Selected wind field and concentration contour plots for the second SF6 release are shown in Figures 14-23. Note that the calculational grid has been shifted so that the release is now in the upper right corner. Figure 14 illustrates the early morning convergence of Snake River Plains drainage flow with surface flow from the south-southeast. This initially brought the SF6 plume to the southwest, guiding it around peaks as high as 2500 feet above the surrounding terrain (Figure 15). As the plume approached the area of convergence it was turned more and more to the west (Figures 16 and 17). As the day progressed the south-southeast winds became better established over most of the domain (Figure 18), and by 1900 UTC they began pushing the plume toward the northwest (Figure 19). Significant directional shear in the upper boundary layer began to be established at this time. The boundary layer flow had been approximately the same as the local surface flow earlier in the day (see Figure 20a). But although some clockwise rotation did occur over the morning hours, by 1830 UTC the 1000 meter flow began to significantly differ from the flow at lower levels (Figure 20b). As the afternoon continued the surface flow began a significant clockwise rotation which caused an even greater difference between the upper and lower wind directions. This effect is further illustrated in Figure 21, where the surface flow in the area of the plume is from due south. Figure 22a shows the modeled surface plume position and Figure $22 \mathrm{~b}$ shows the modeled plume at 1000 meters above the surface for the same time. Note that the contours shown in Figure $22 \mathrm{~b}$, in addition to being much further to the south-southwest, are also much less in magnitude (1.0 and $0.1 \mathrm{ppt}$ ). Even though the directional shear in the upper levels occurs above the aircraft flight altitudes, transport of the measured plume may have been affected by the SF6 moving into and out of these higher layers. By the end of the experiment the surface flow over most of the domain was from the southwest (Figure 23), although indications of surface flow from the northeast coming out of the southern end of the Snake River Plains is still evident.

\section{Surface Measurement Comparison}

Again, inspection of the calculated 10 ppt concentration contours was made for comparison to the truck and aircraft measurements. Truck hits and misses are shown in Figure 24. At the time of the first measurement (1335 UTC) the modeled plume is quite narrow and is shown over Big Lost River with the plume boundary very close to, if not over, the measurement point. By 1420 UTC the plume is directly over the truck location and agrees with the measurement hit. At 2015 UTC the $10 \mathrm{ppt}$ plume covers the truck location, although the boundary is just to the south of the measurement miss. The plume clearly covers the 2028 UTC sampling location, matching that measurement hit. However by 2216 UTC the modeled plume is well to the north of the truck location. (There is an indication in the log that the plume was found at the 2216 UTC location, but no concentration value is listed.) 


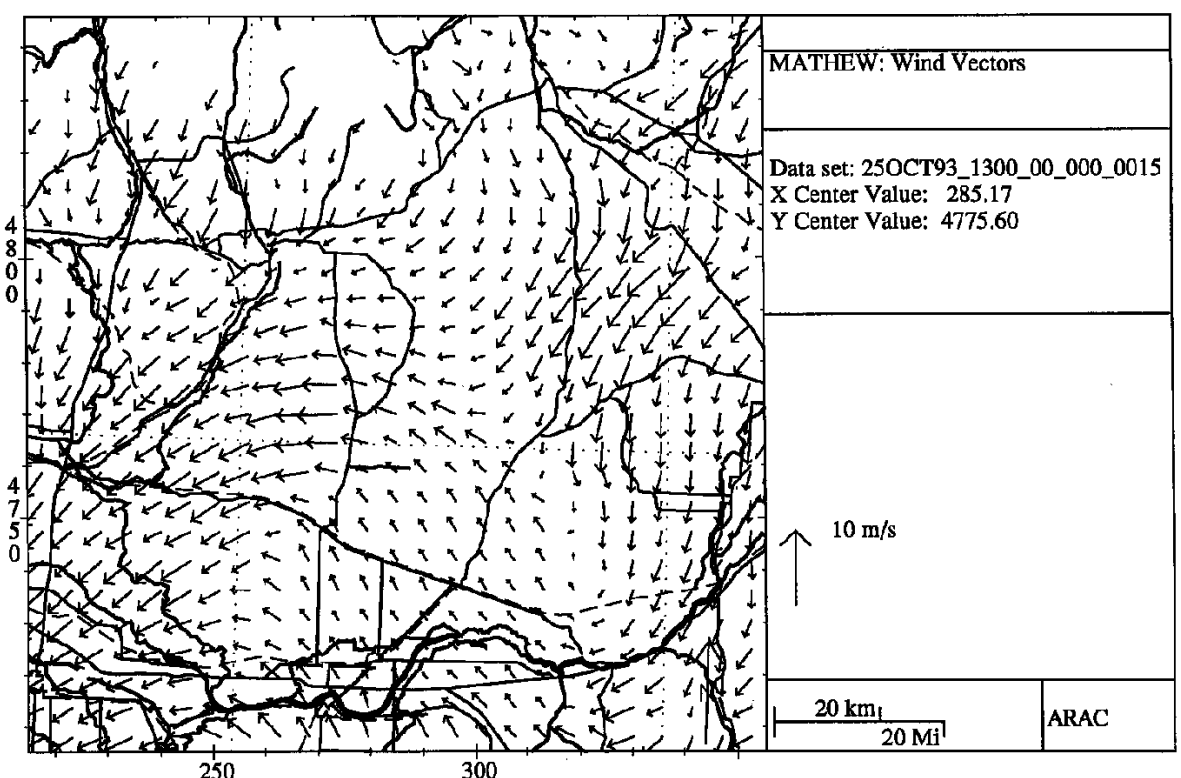

Figure 14. Modeled near-surface wind field for Release \#2 at 1300 UTC.

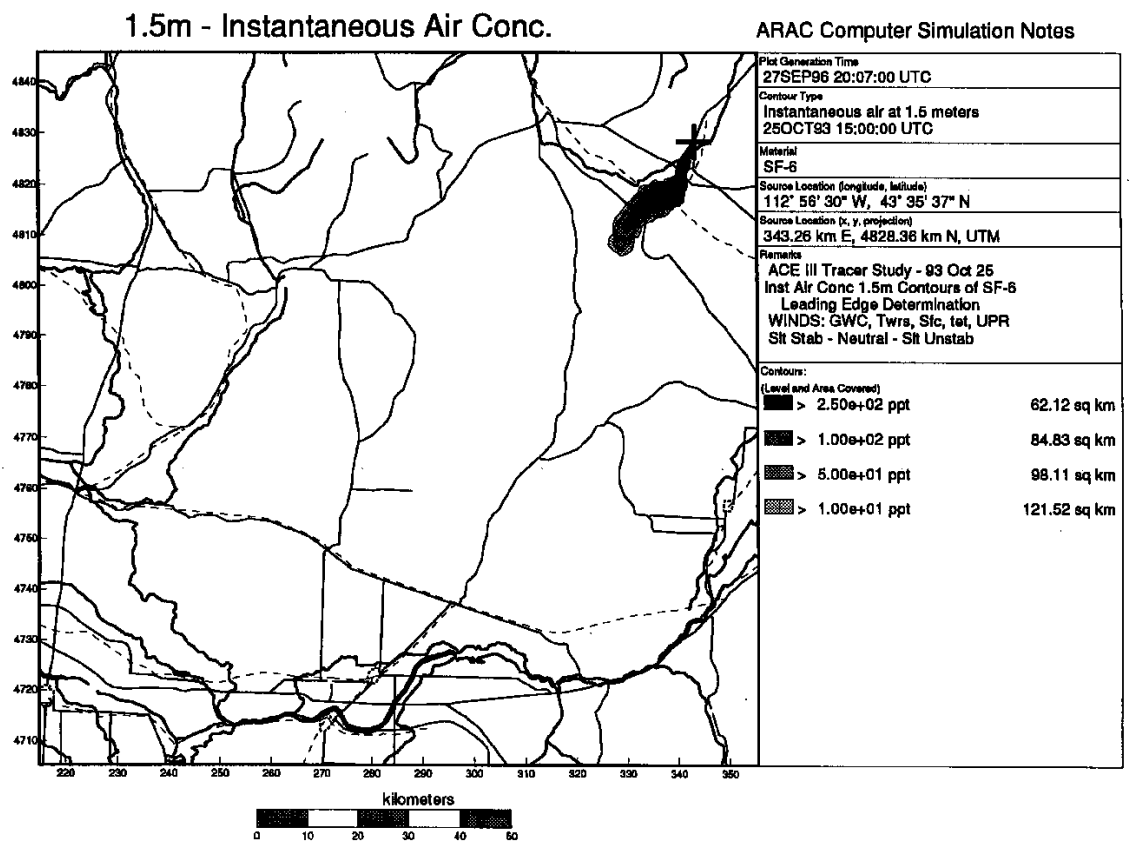

Figure 15. Modeled SF6 surface air concentrations (in ppt) for Release \#2 at 1500 UTC. 


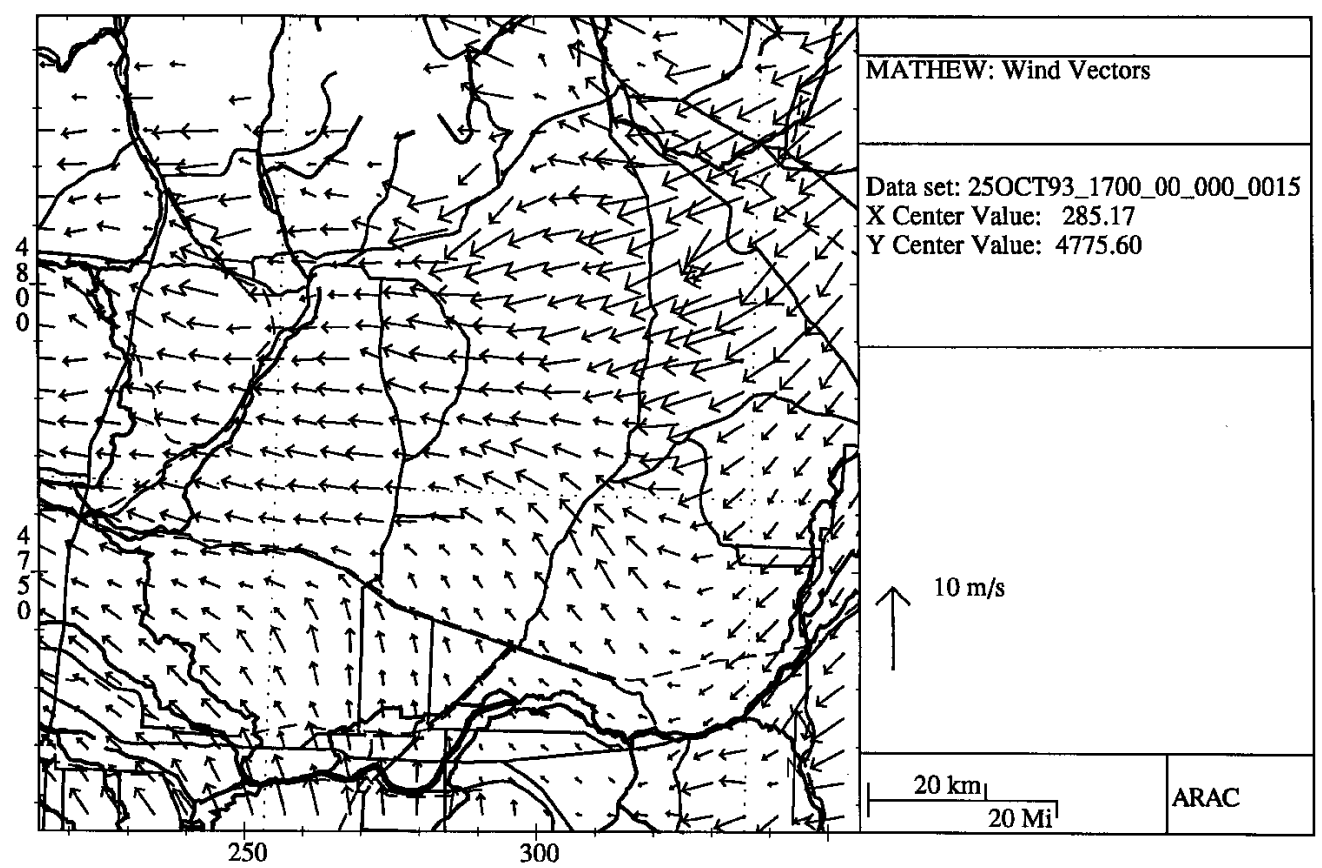

Figure 16. Modeled near-surface wind field for Release \#2 at 1700 UTC.

$1.5 m$ - Instantaneous Air Conc.

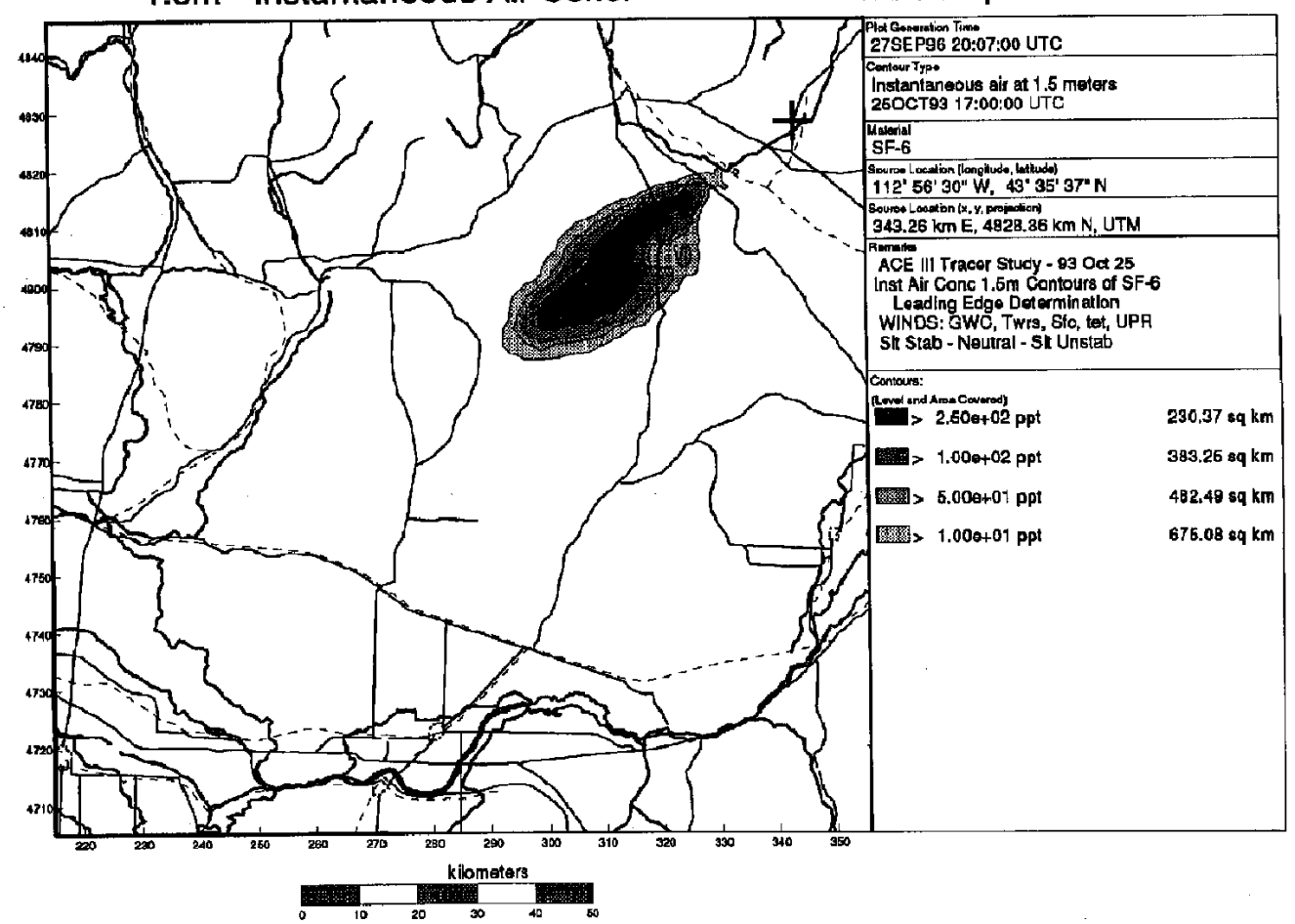

Figure 17. Modeled SF6 surface air concentrations (in ppt) for Release \#2 at 1700 UTC. 


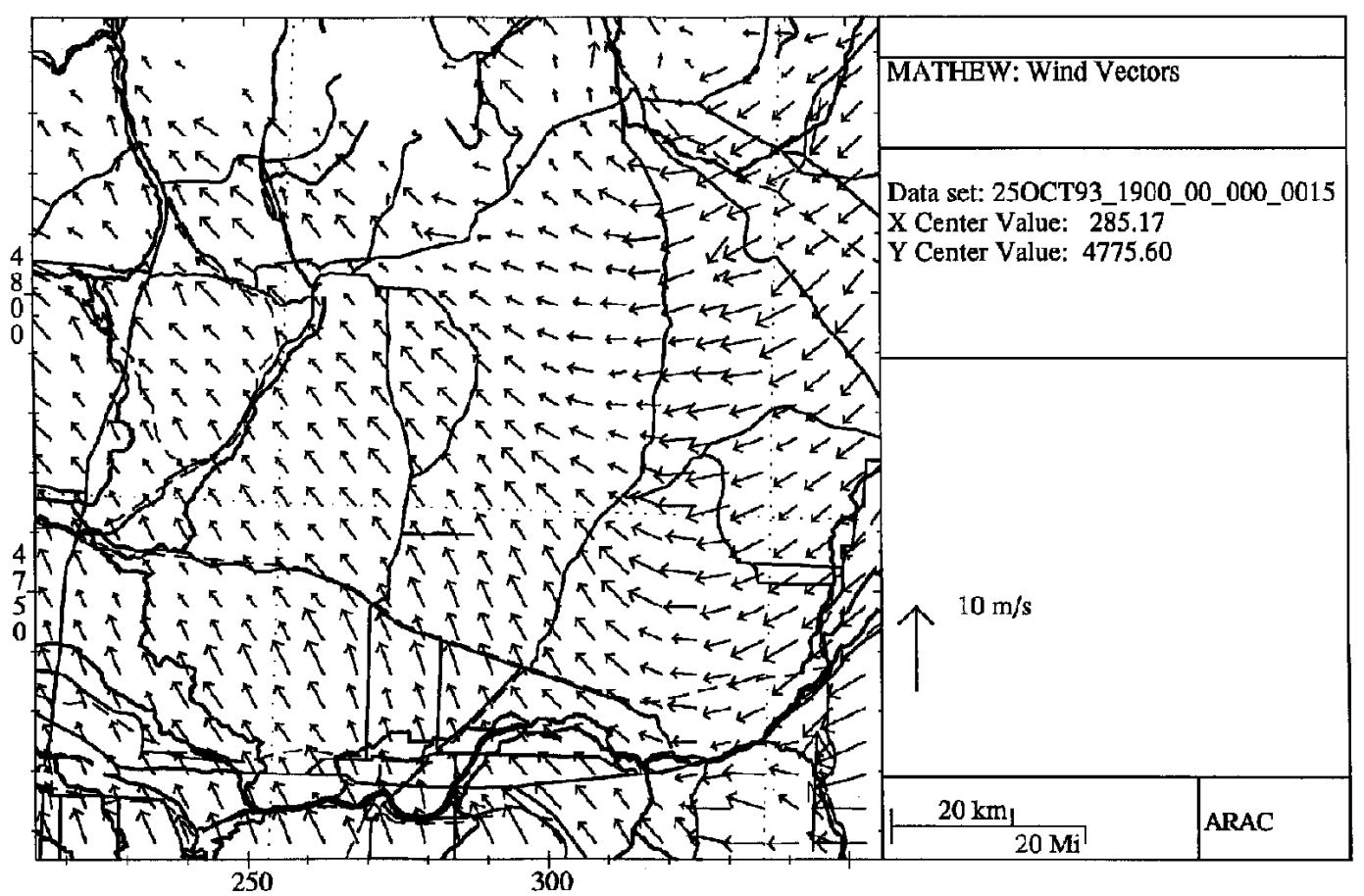

Figure 18. Modeled near-surface wind field for Release \#2 at 1900 UTC.

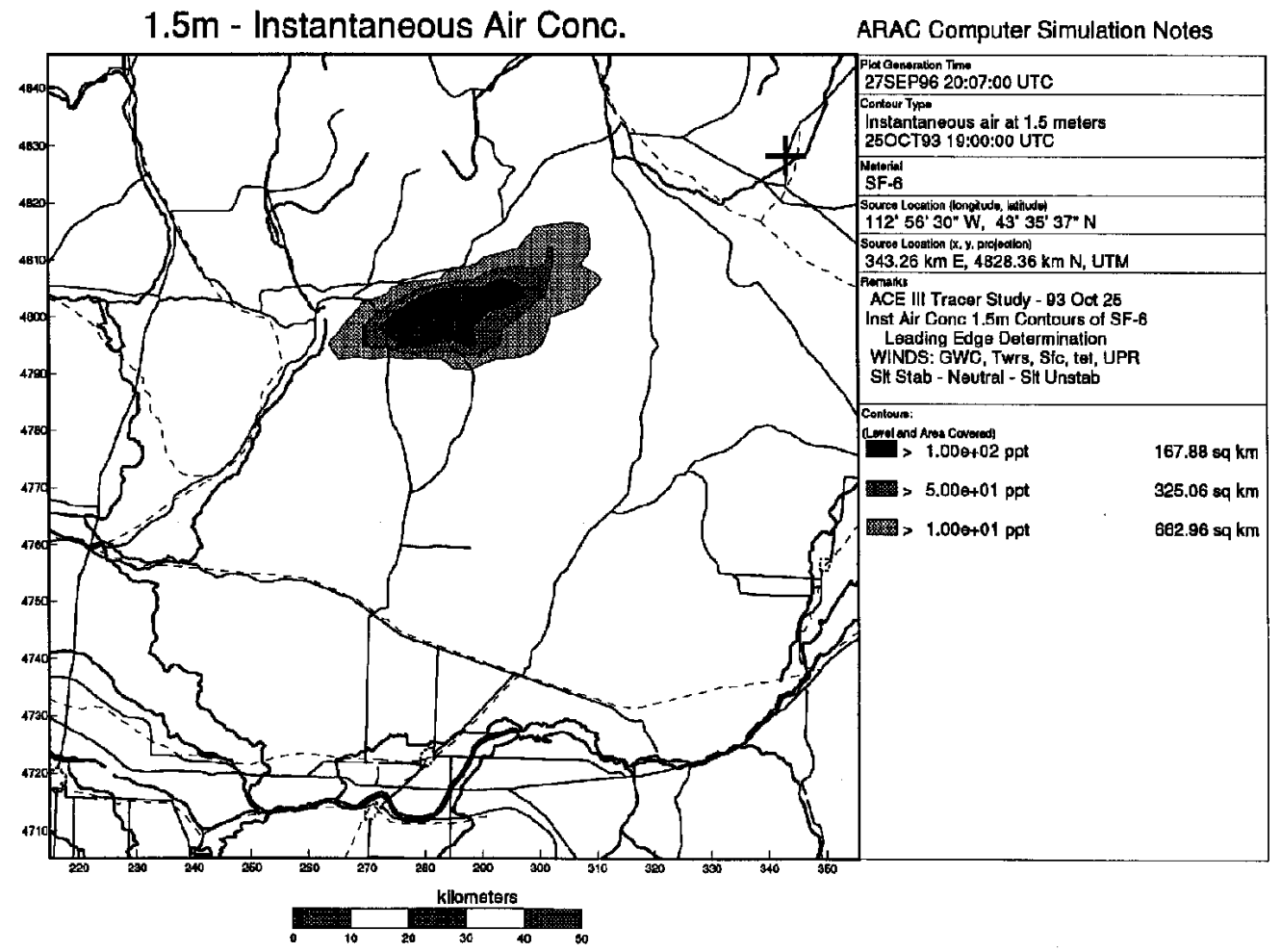

Figure 19. Modeled SF6 surface air concentrations (in ppt) for Release \#2 at 1900 UTC. 
(a)

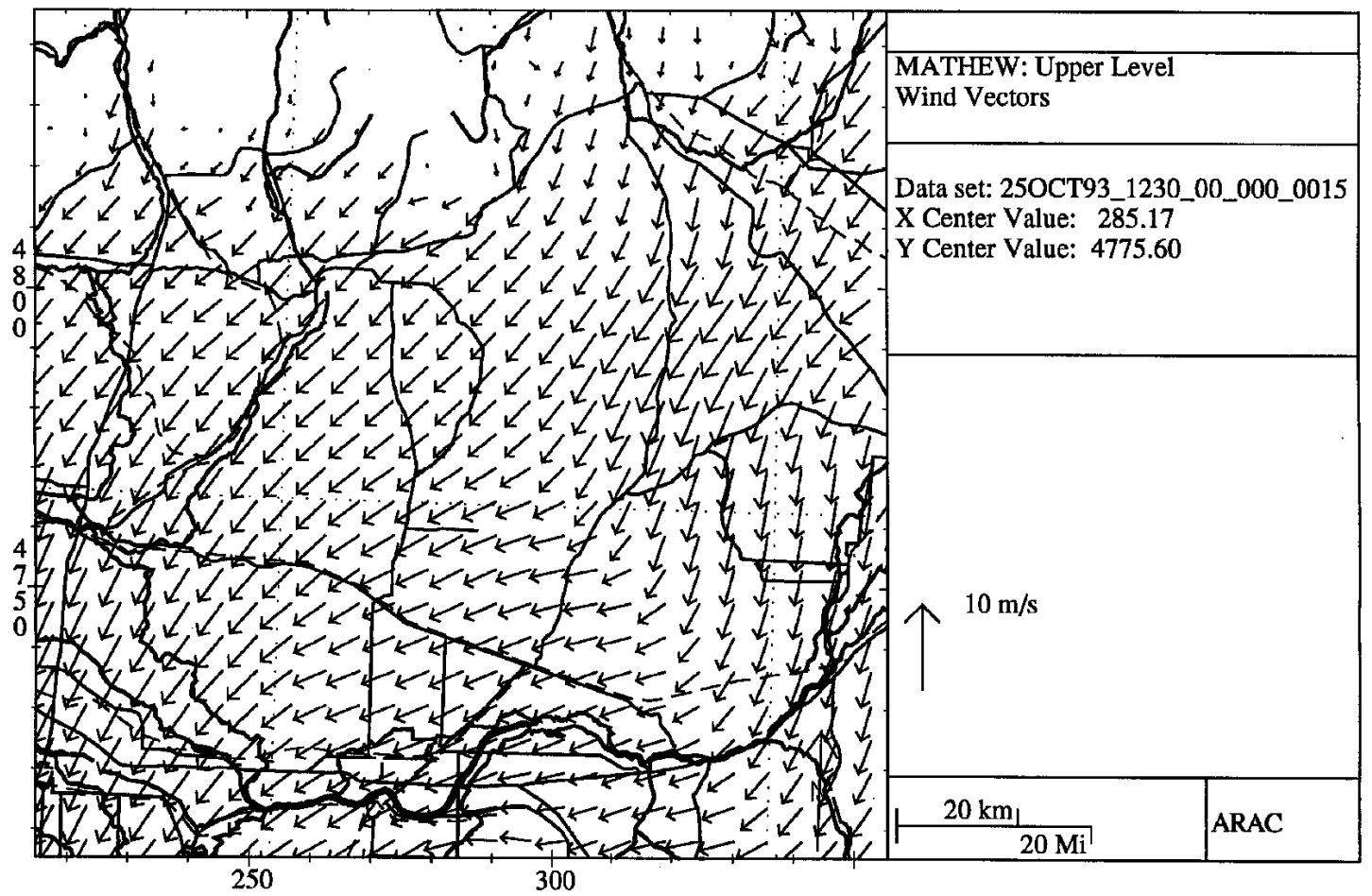

(b)

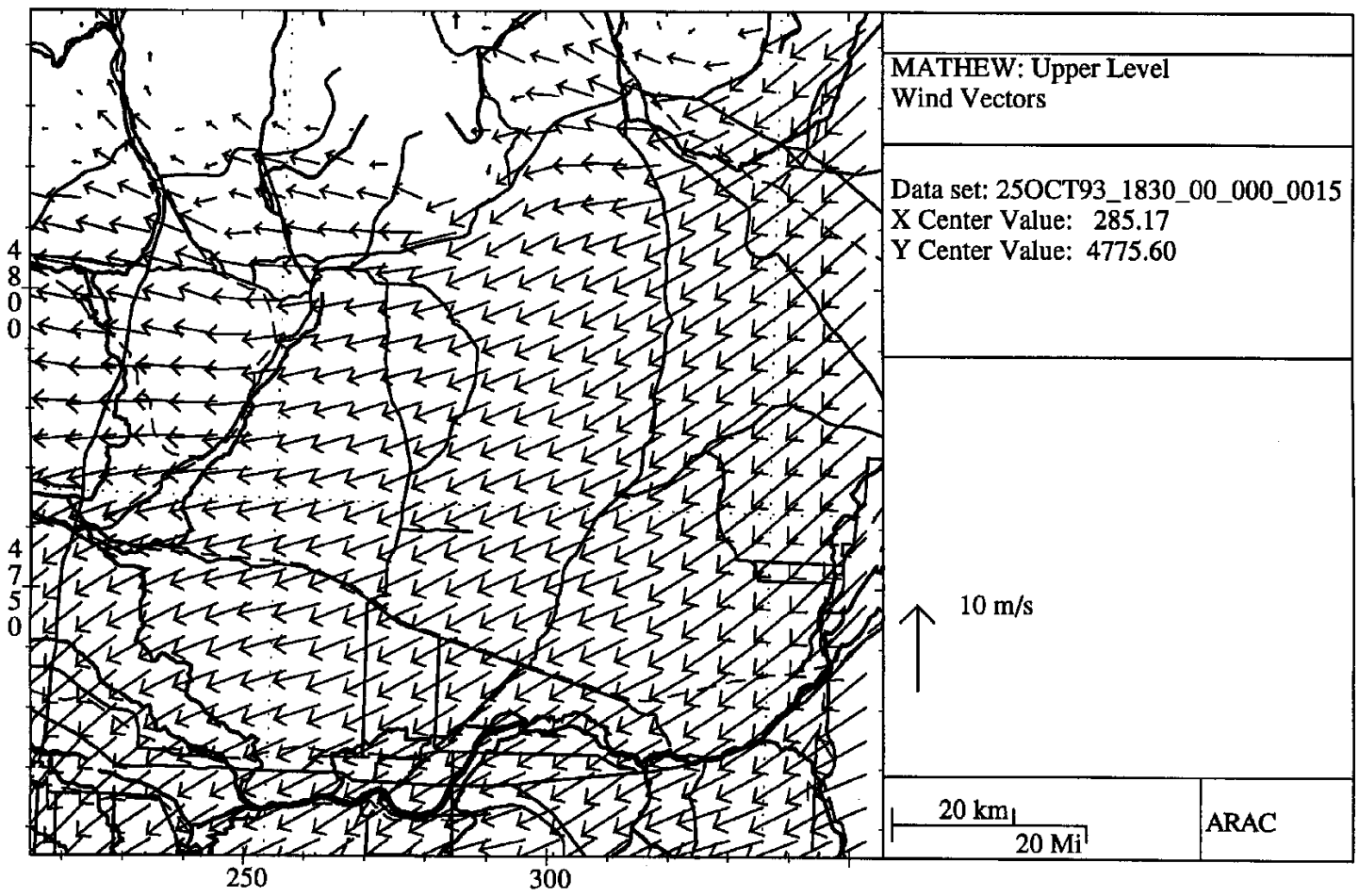

Figure 20. Modeled wind field 1000 meters above the surface for Release \# 2 at (a) 1230 UTC, and (b) 1830 UTC. 


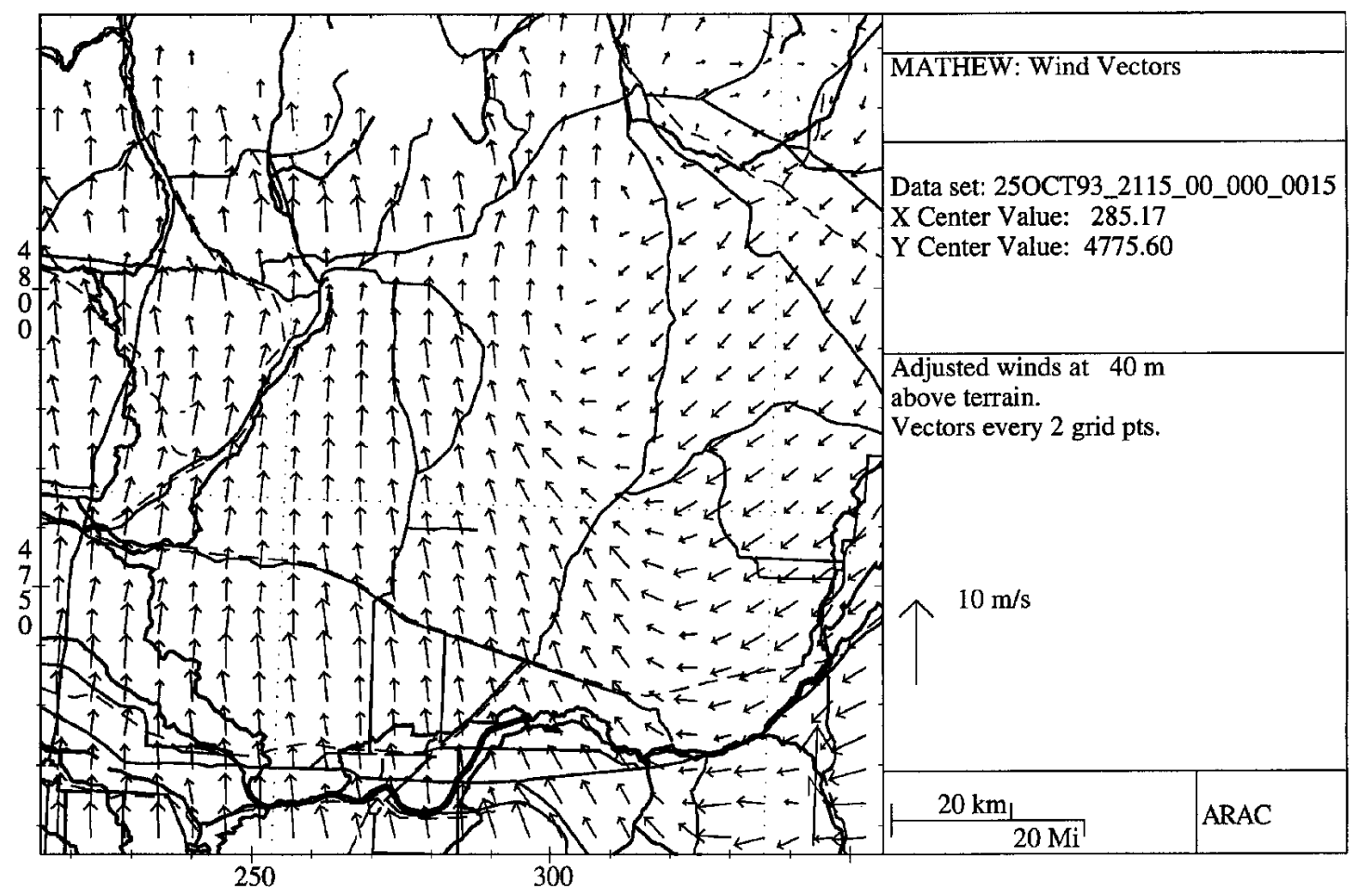

Figure 21. Modeled near-surface wind field for Release \#2 at 2115 UTC.

\section{Airborne Measurement Comparison}

Figure 25 shows the aircraft locations and approximate times when no measurable SF6 was sampled. As was the case for the first release, the model agrees with all of the aircraft miss data as the modeled 10 ppt contours do not cover these areas at the appropriate flight altitudes. Figure 26 shows the aircraft hits. The hits have been split into three approximate groupings. Model calculations agree with those included in region A. These measurements were taken primarily from about 1855 to 1905 UTC, with the very northern measurements taken at about 1925. The modeled $10 \mathrm{ppt}$ contour boundary is found to run along the south and west edges of this region, with higher concentrations to the northeast of the region. Those measurements shown grouped by the letter B were taken between about 1925 and 1950 UTC. By this time the modeled plume had moved too far northwest to match these data. The calculated plume, at the corresponding altitudes, never moved into the region in which the other measurements (grouped by the letter C) were taken. As can be seen from Figure 26, calculations would have better matched these westernmost measurements (taken over periods ranging from about 1905 to 2045 UTC) if the plume had moved more to the west during these times. The reader may recall that this was the period in which significant directional shear occurred at the upper levels of the calculational domain. Longer actual residence times of the SF6 at these higher levels (where winds had more of a component to the west) than what was simulated by the model calculations could have led to this discrepancy. 
(a)

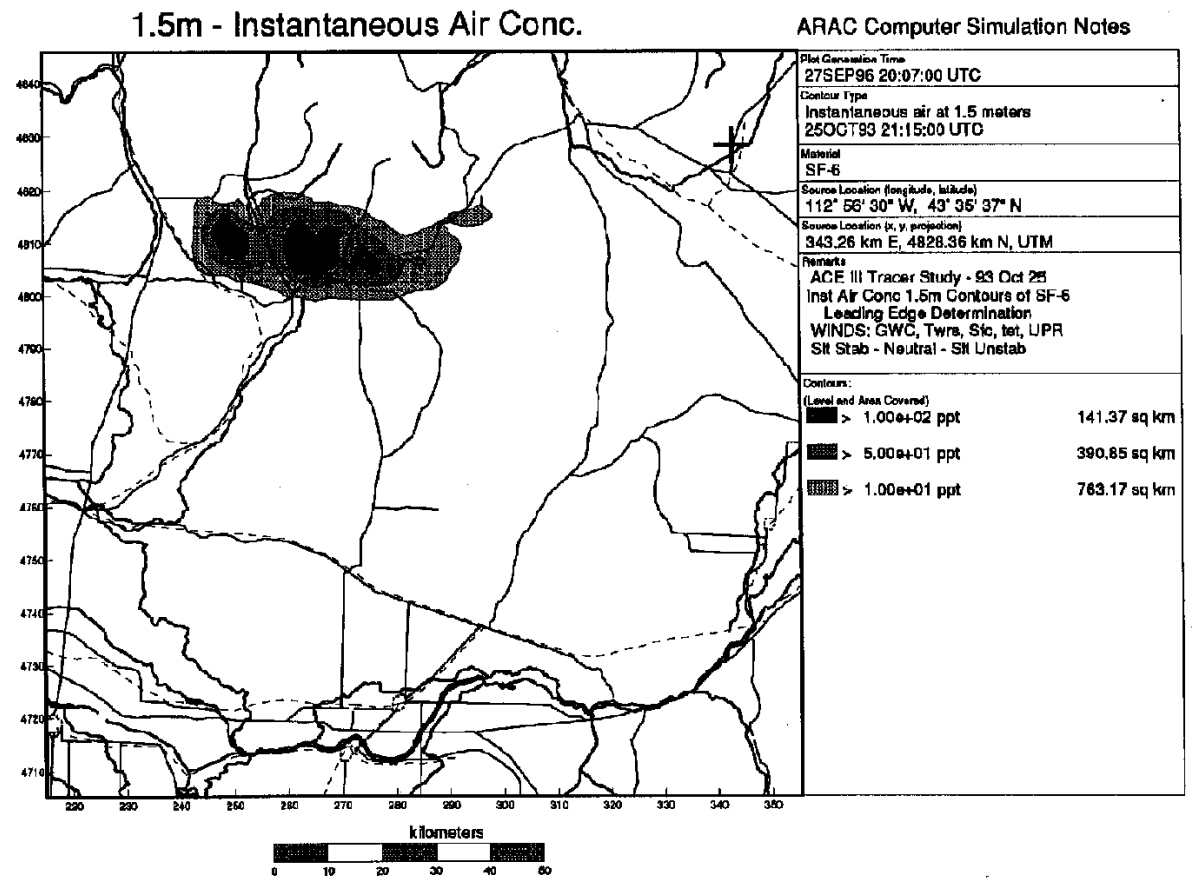

(b)

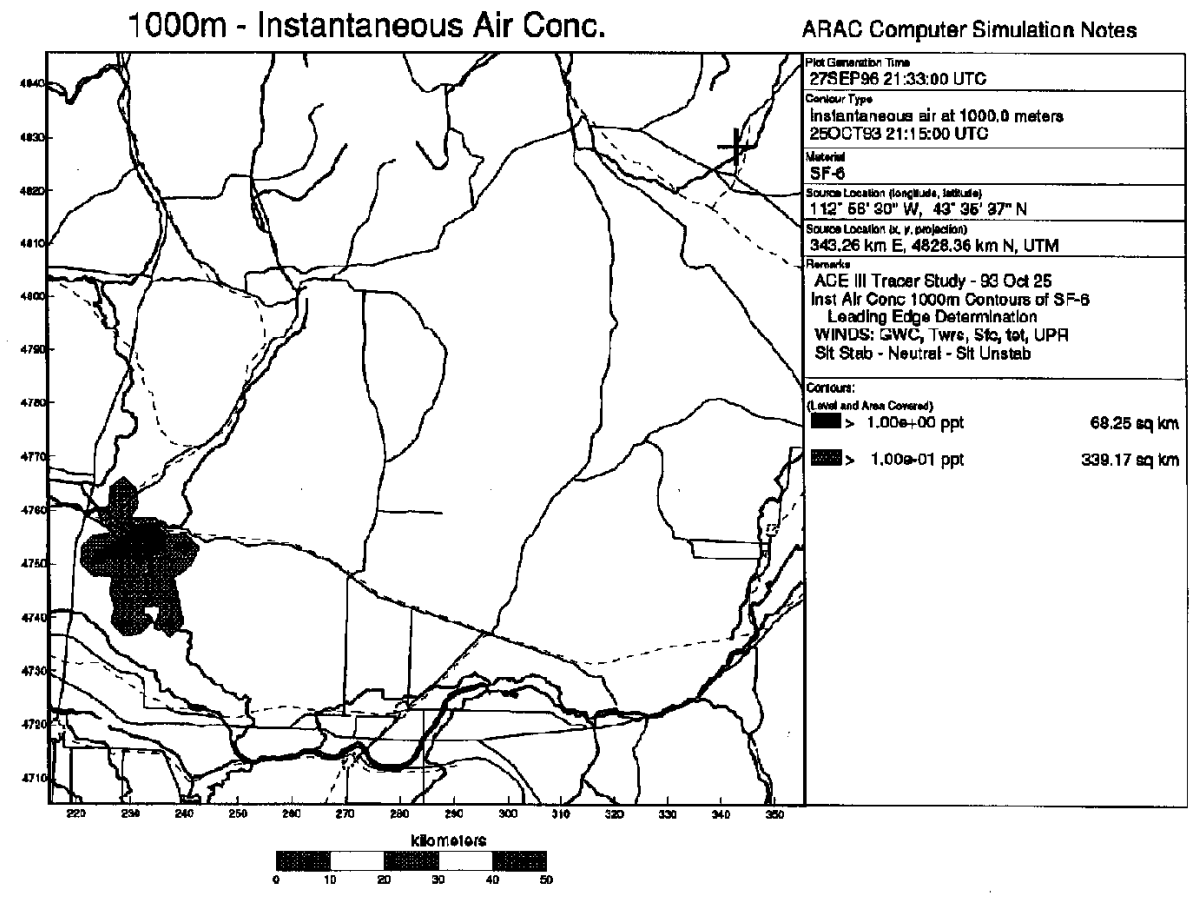

Figure 22. Modeled SF6 air concentrations (in ppt) for Release \#2 at 2115 UTC (a) at the surface, and (b) at 1000 meters above the surface. 


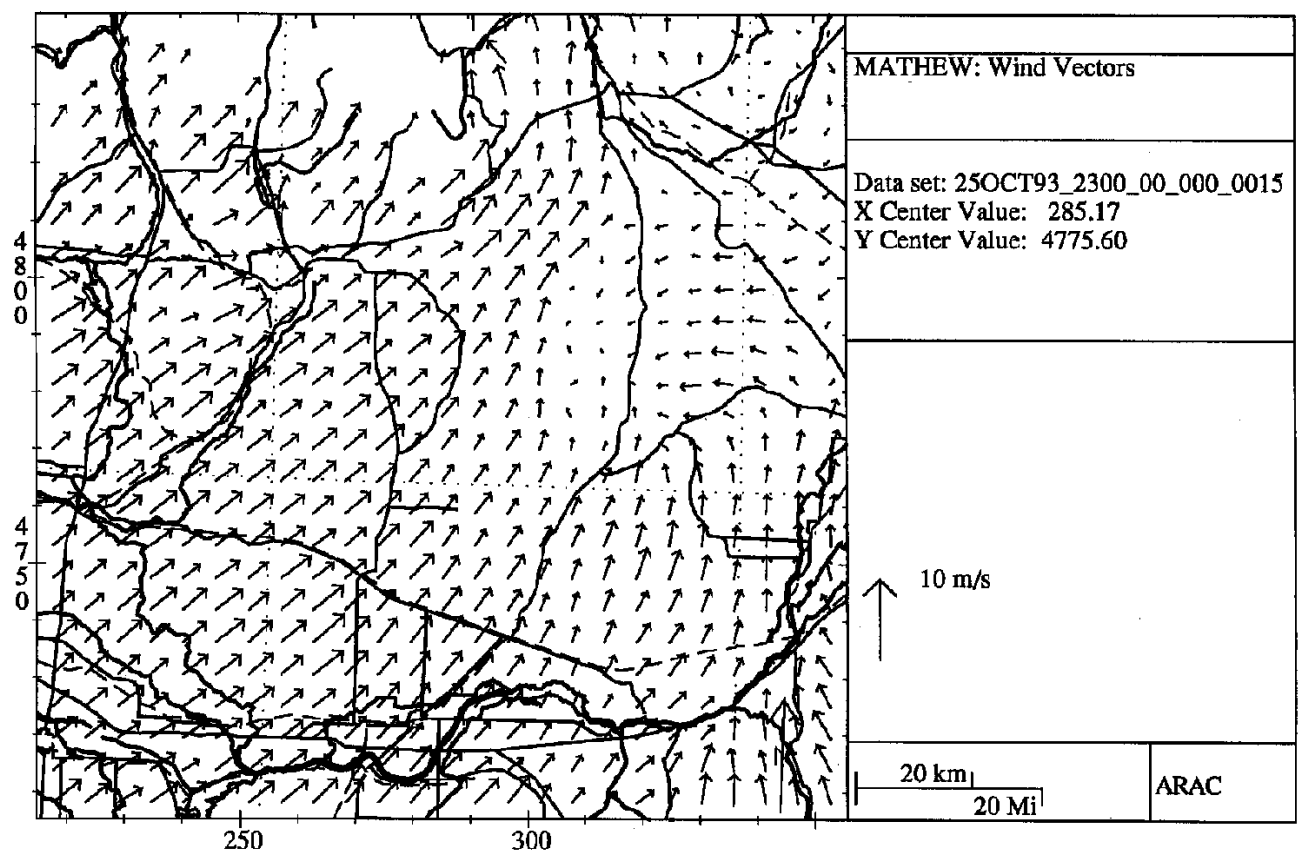

Figure 23. Modeled near-surface wind field for Release \#2 at 2300 UTC.

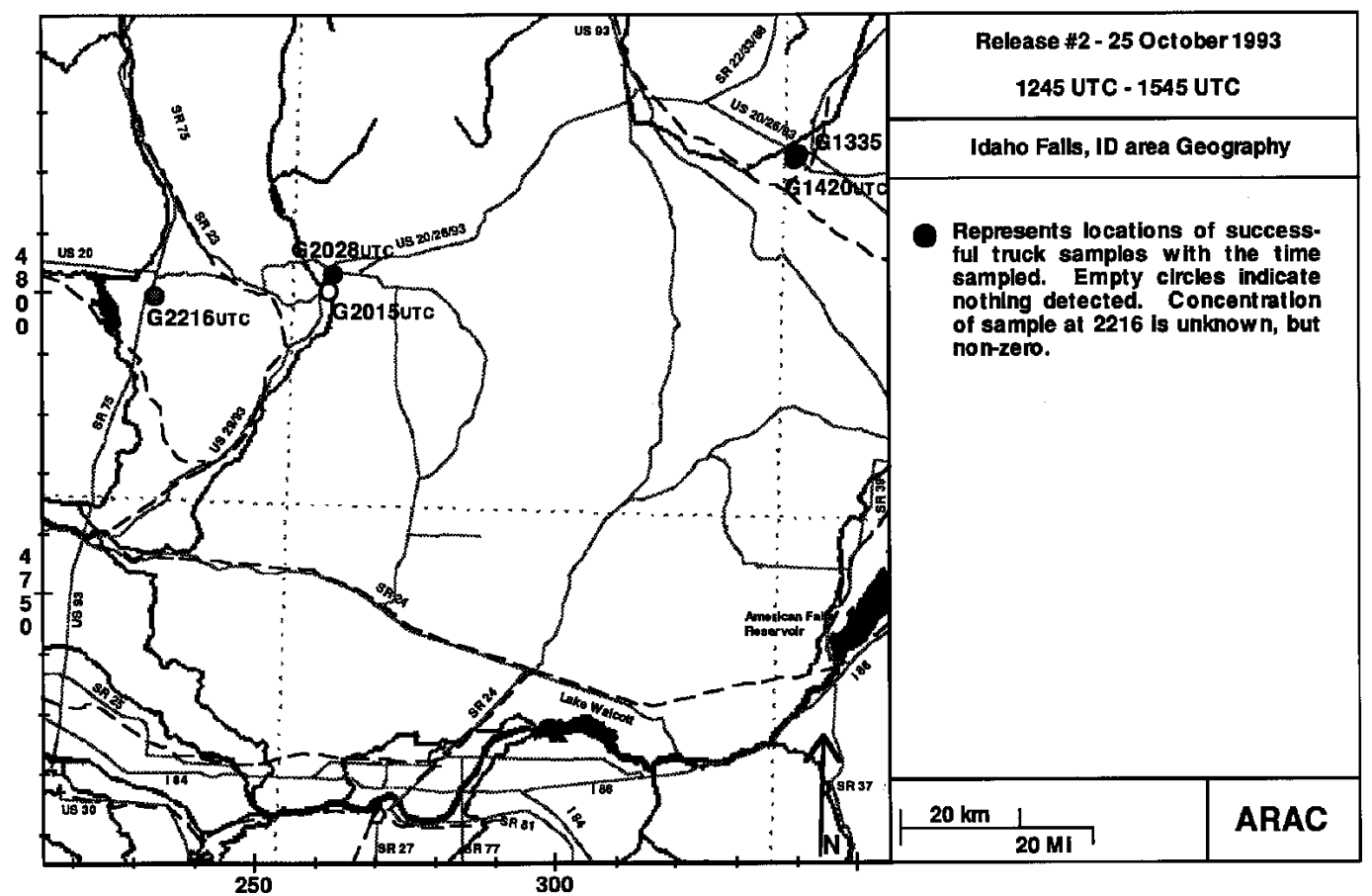

Figure 24. SF6 surface measurements for Release \#2. Solid circles indicate locations of plume "hits" (e.g. measurement of at least $10 \mathrm{ppt}$ ). Empty circles indicate locations of plume "misses" (e.g. measurement less than $10 \mathrm{ppt}$ ). The times of the measurements are indicated for each location. 


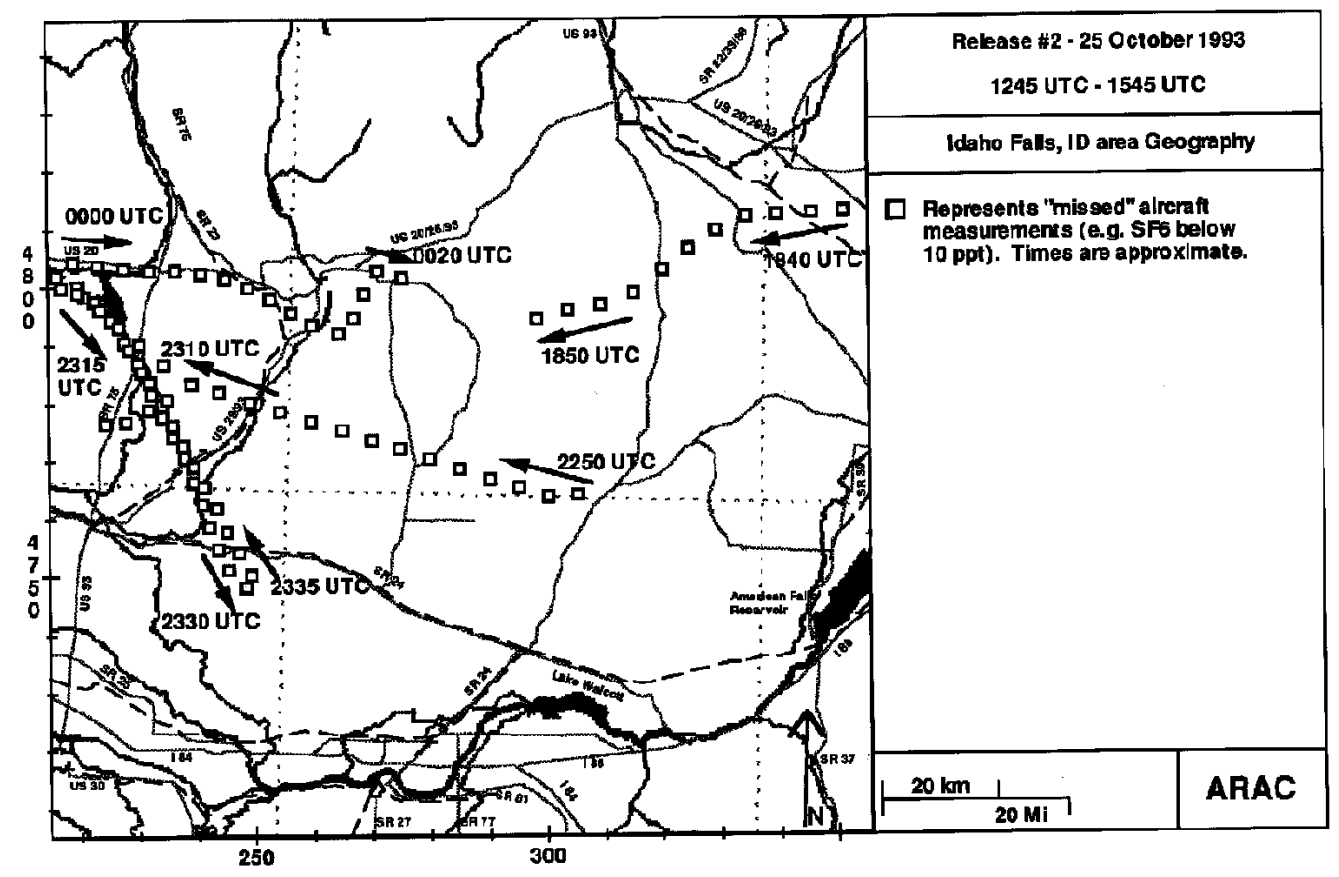

Figure 25. SF6 aircraft plume "misses" (measurements less than $10 \mathrm{ppt}$ ) for Release \#2. The approximate times of the measurements are indicated.

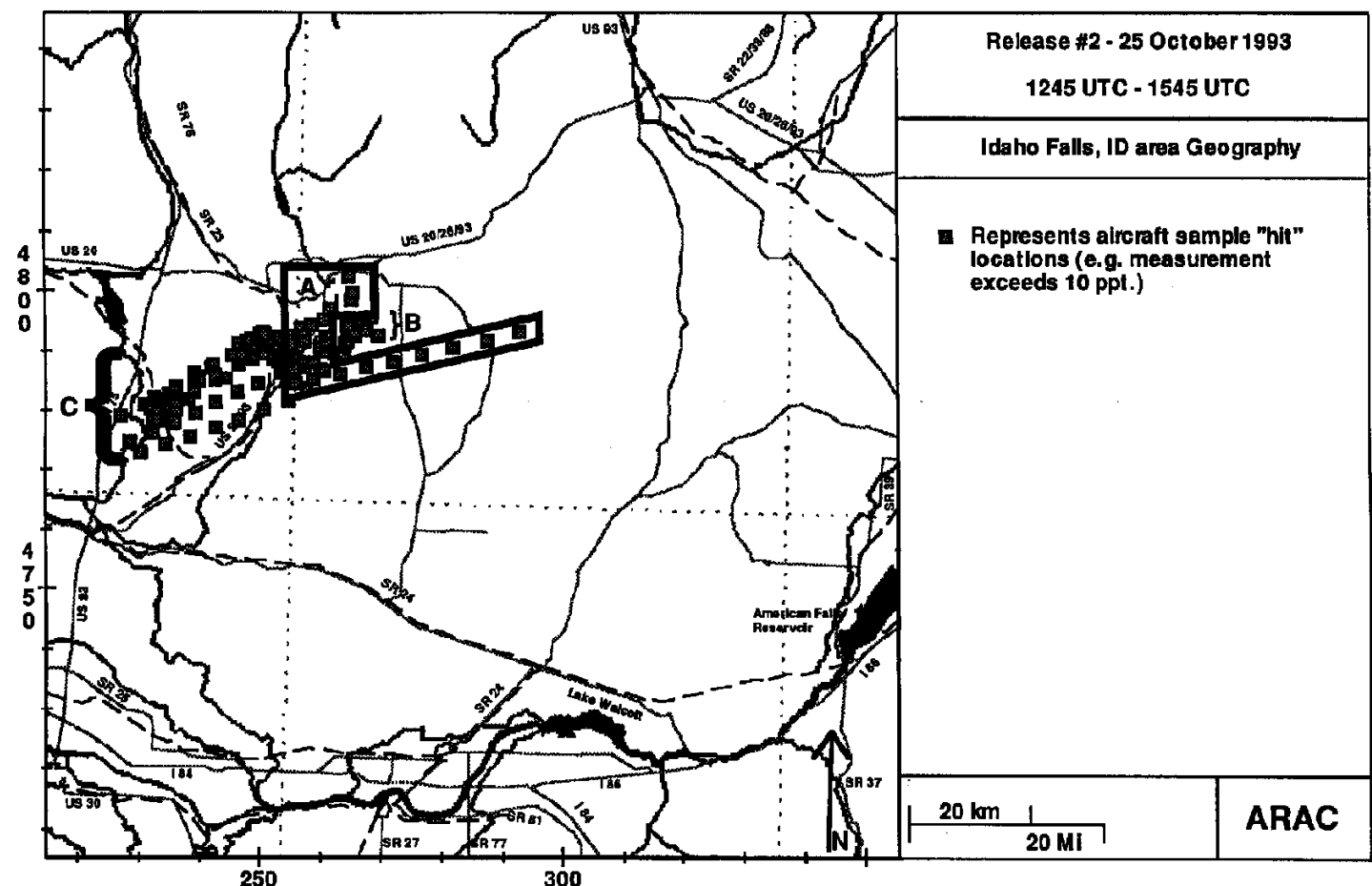

Figure 26. SF6 aircraft plume "hits" (measurements of at least $10 \mathrm{ppt)}$ for Release \#2. 


\section{SF6 Release 3}

\section{Modeled Wind Flow Pattern}

The wind flow during the third SF6 release was somewhat similar to that of the second release. Figures 27-33 show selected wind field and contoured concentration plots for the third release. As with the second release, the initial flow was to the southwest (Figures 27 and 28). In this case, however, the surface flow was fairly uniform over the entire domain, with the first several hours showing no area of wind convergence as was found in the case for the second release. As the day progressed the winds again began a clockwise rotation, bringing more of a westward plume movement that followed a path quite similar to release number two (Figures 29 and 30). Note that the plume is much more elongated in the east-west direction due to relatively strong speed shear in the lower boundary layer. By 2100 UTC plume movement was principally to the north as a strong anti-cyclonic (clockwise) curvature to the flow develops in the southwestern part of the domain. As the afternoon continues the surface flow becomes fully anti-cyclonic with the center of the rotation drifting toward the northeast (Figure 31). By the end of the experiment the elongated plume has been sheared by the changing surface and upper level flows so that the westernmost plume continues its northward movement, while the eastern edge of the plume doubles back toward the northeast, toward the Snake River Plains (Figure 32). For reference, the upper level flow at the beginning and end of the experiments is shown in Figure 33.

\section{Surface Measurement Comparison}

The truck measurements for this third release are shown in Figure 34. Model calculations reproduce this hit and miss pattern extremely well. The plume (at the corresponding times) remains well to the northeast of the first two measurement locations (at 1703 UTC and 1728 UTC). The modeled plume boundary runs through the 1822 UTC measurement location at 1815 UTC, and by 1845 UTC has moved further to the south to cover the 1845 UTC measurement location. The calculations also place the plume over the 2215 UTC and 2240 UTC sample hit locations.

\section{Airborne Measurement Comparison}

Aircraft measurement patterns are also recreated quite well. Figure 35 shows the aircraft locations and approximate times when no measurable SF6 was sampled. For the vast majority of these points the model calculations agree with the data. In a few instances the sampled locations just cross over the modeled plume edge at the corresponding heights and times. This occurs for the 2-3 northernmost points sampled on the 1650 UTC run, a few of the early points in the area sampled from 2100 to 2115 UTC when the aircraft was at about 200 meters above the surface (model calculations agree with the data during this period when the aircraft was above 200 meters), and perhaps for 1 or 2 points along the 2125 to 2150 UTC flight path which fall in the same area as a very spotty modeled southern plume boundary. At other times and locations the modeled plume stayed to the north and/or east of the remaining measurement miss points, with greater northward movement of the plume at the higher levels. This directional shear can be inferred from the upper air pattern shown in Figure 33b.

Figure 36 shows the aircraft locations for the SF6 measurement hits. Model calculations agree with the greater than 10 ppt measurements in regions $\mathrm{A}$ through $\mathrm{D}$. Region A outlines measurements taken at about 1655 UTC. These were taken in the same area as the 2-3 1650 UTC measurement misses highlighted above, reflecting the fact that the plume boundary was in this area as predicted by the model. Points in region B were sampled from about 1700-1705 UTC and fall within the modeled $10 \mathrm{ppt}$ contour. Region C 


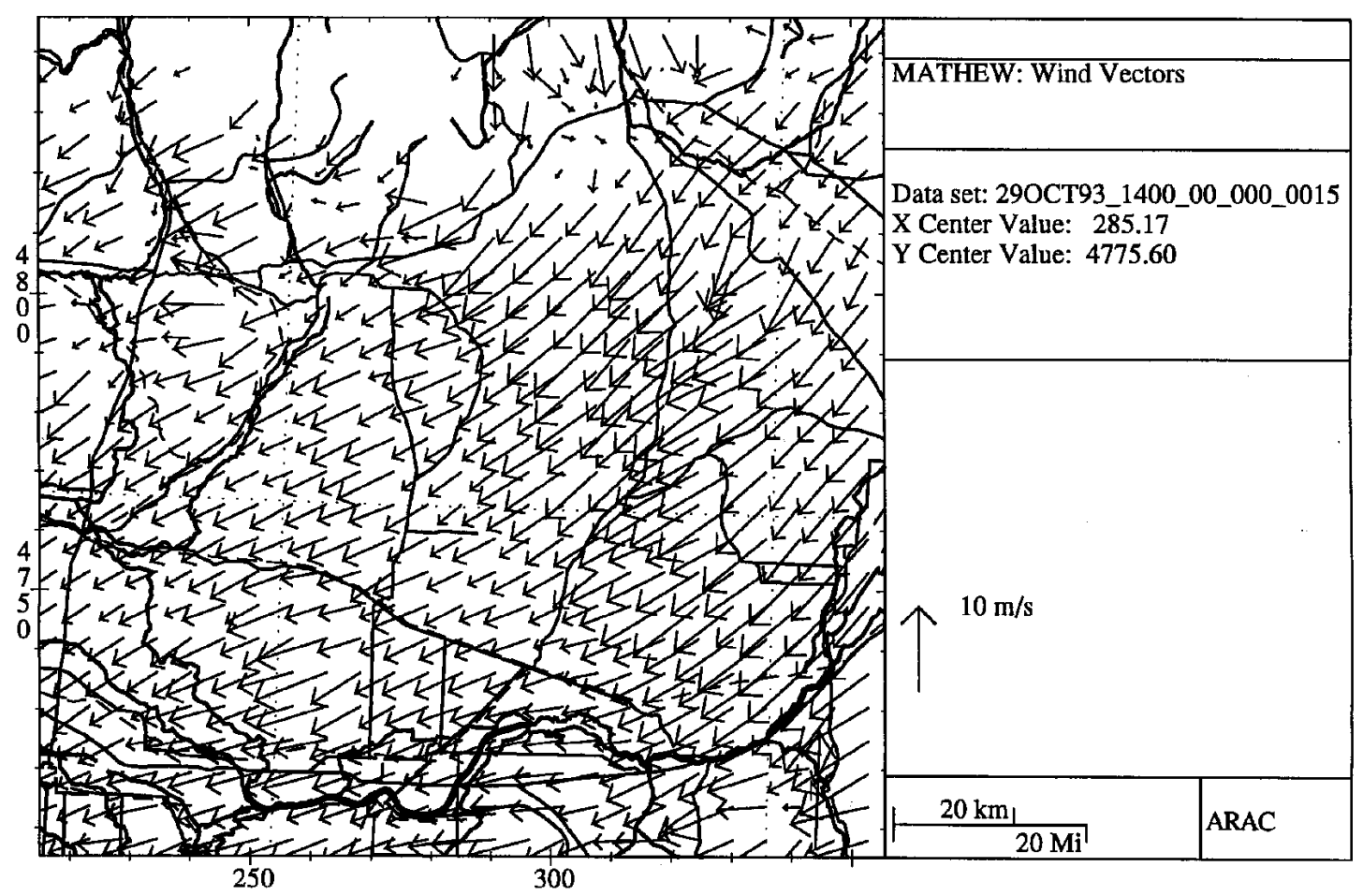

Figure 27. Modeled near-surface wind field for Release \#3 at 1400 UTC.

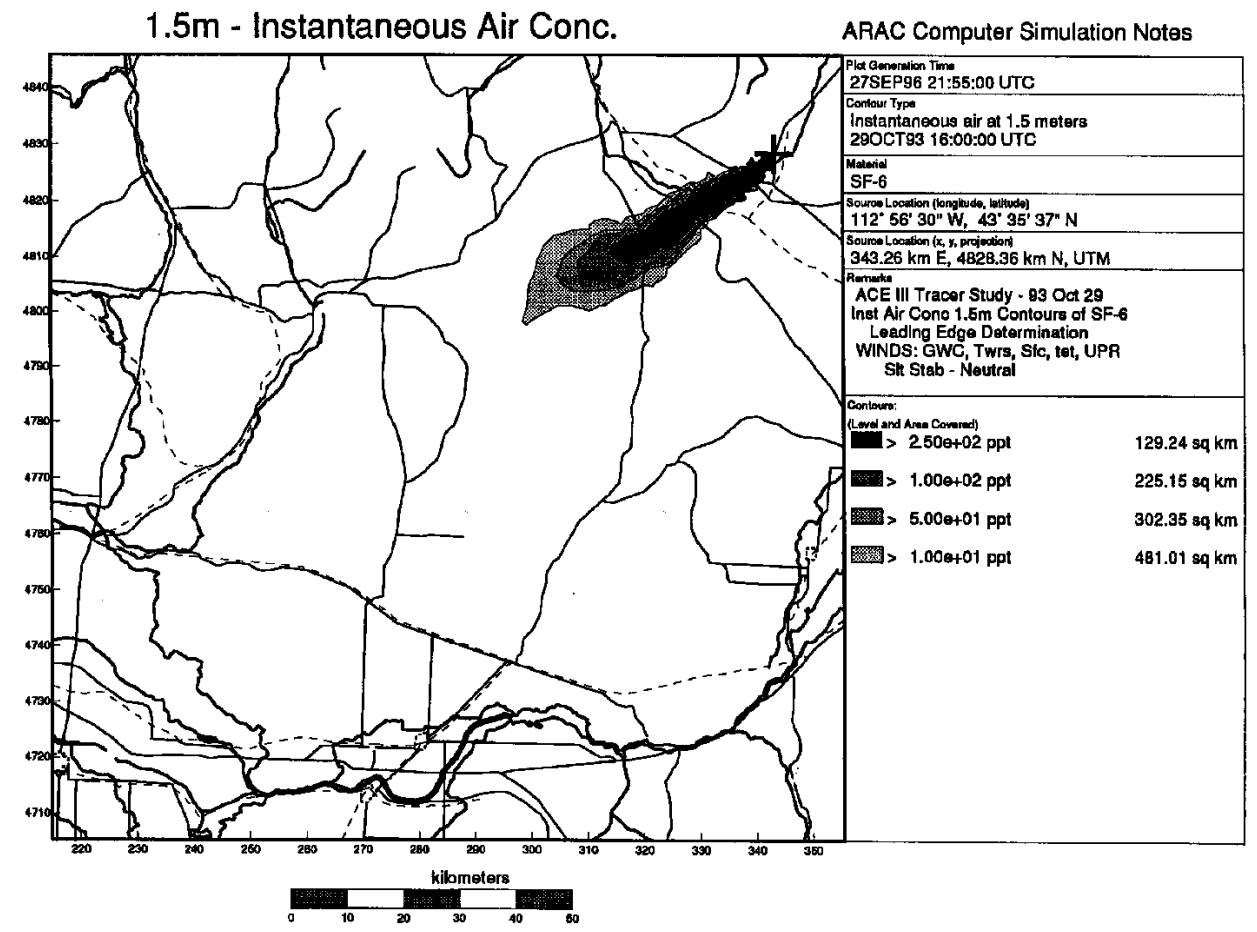

Figure 28. Modeled SF6 surface air concentrations (in ppt) for Release \#3 at 1600 UTC. 


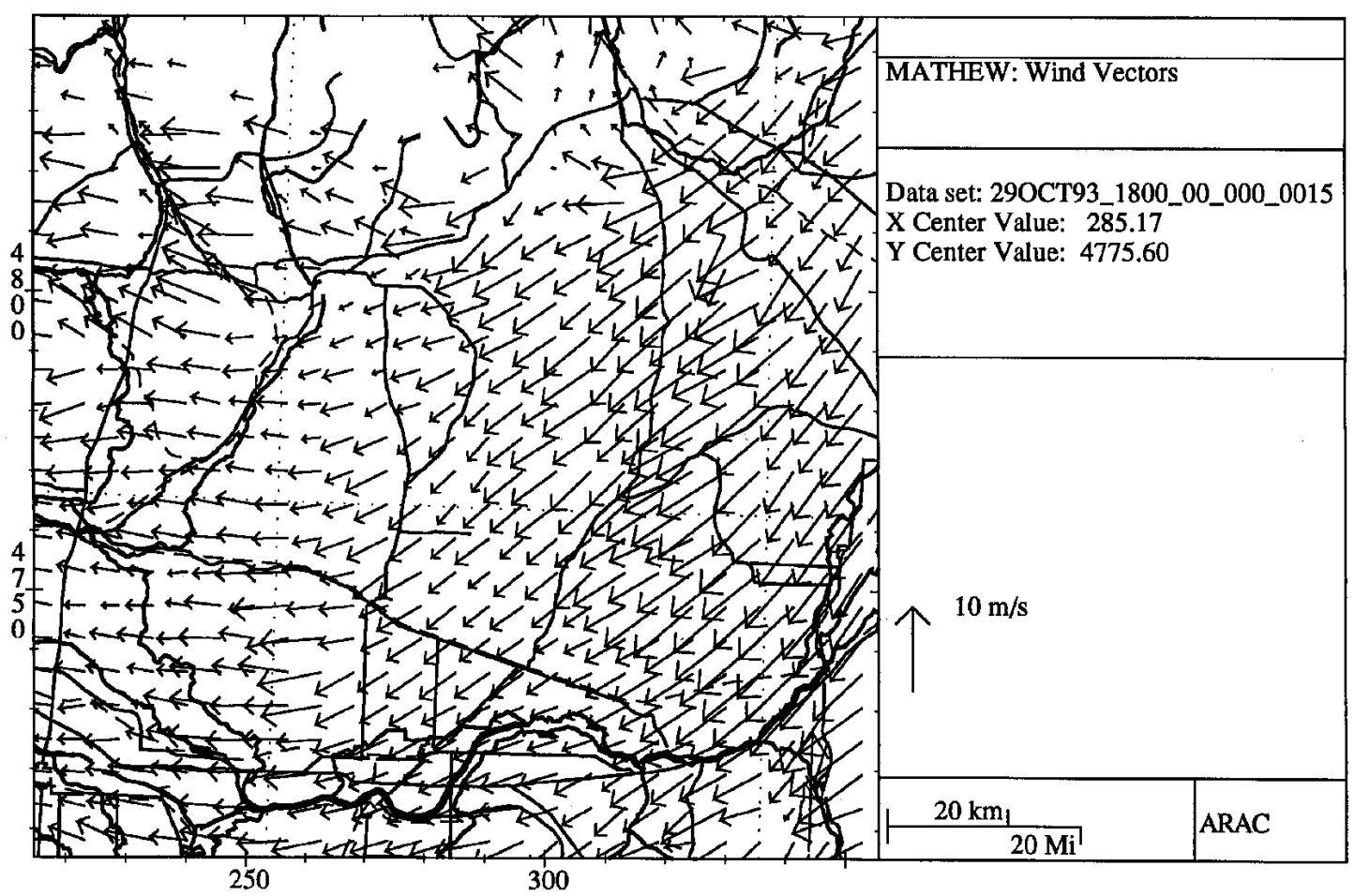

Figure 29. Modeled near-surface wind field for Release \#3 at 1800 UTC.

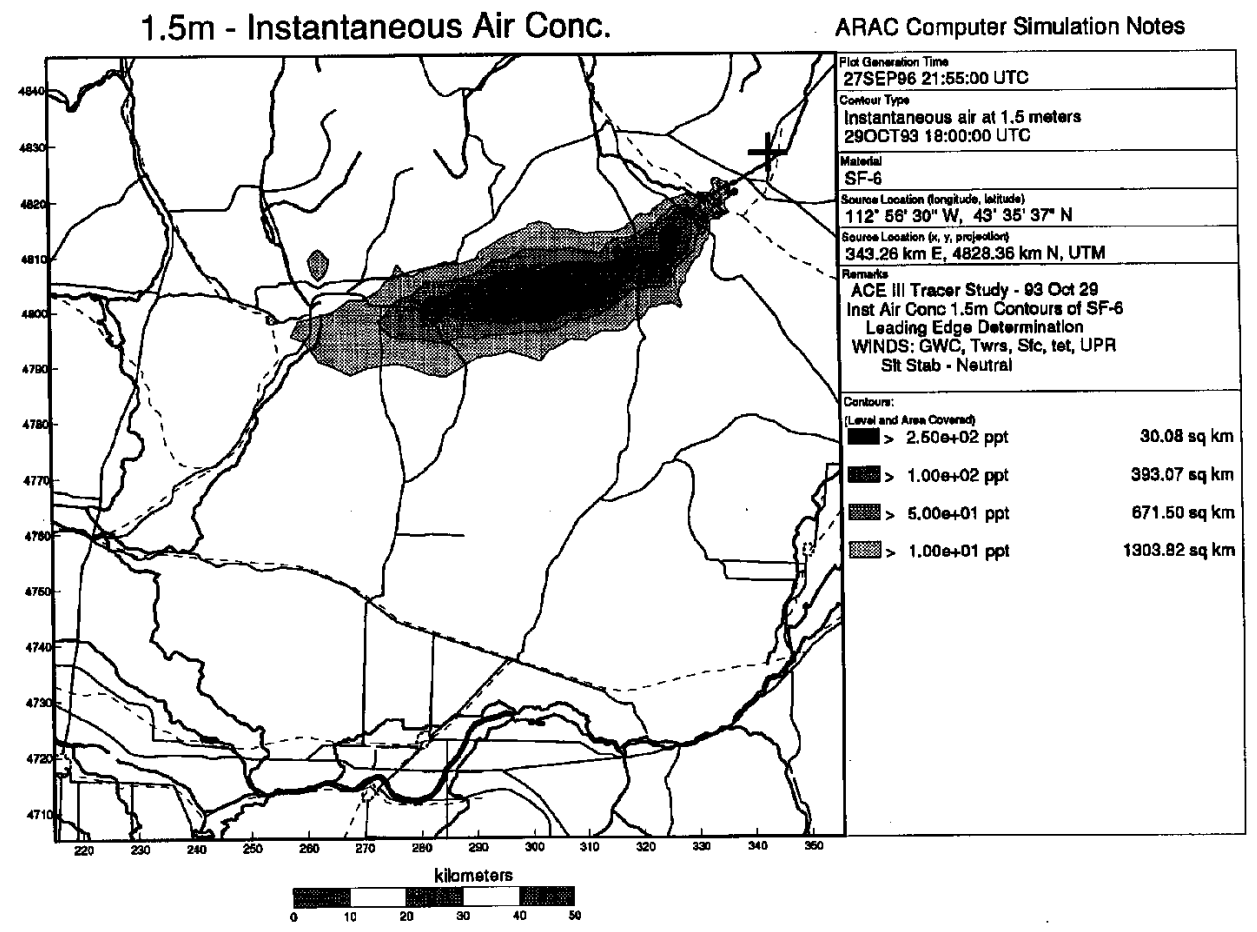

Figure 30. Modeled SF6 surface air concentrations (in ppt) for Release \#3 at 1800 UTC. 
(a)

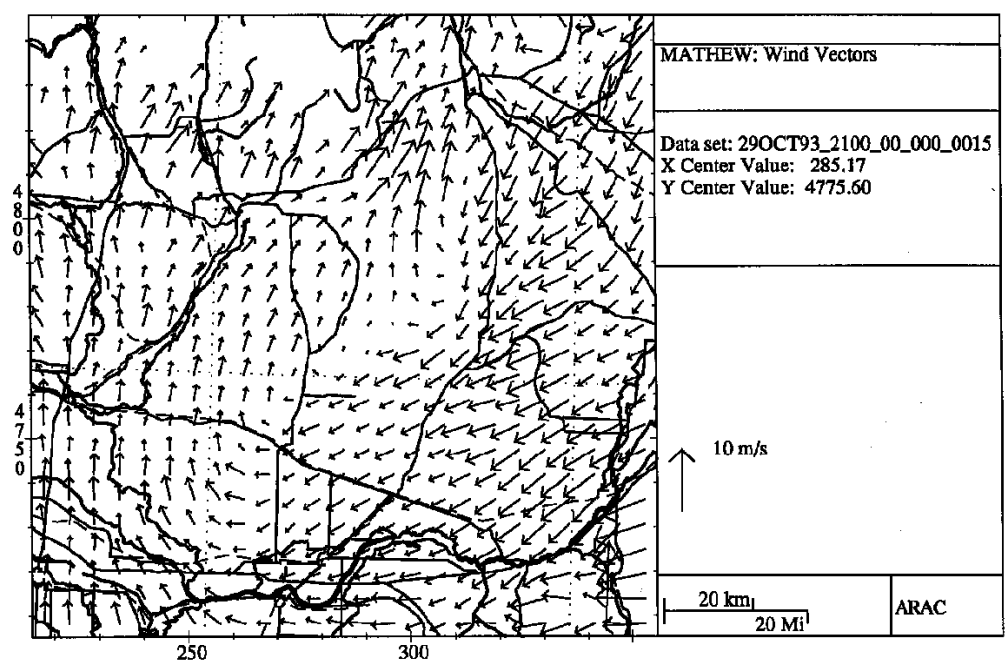

(b)

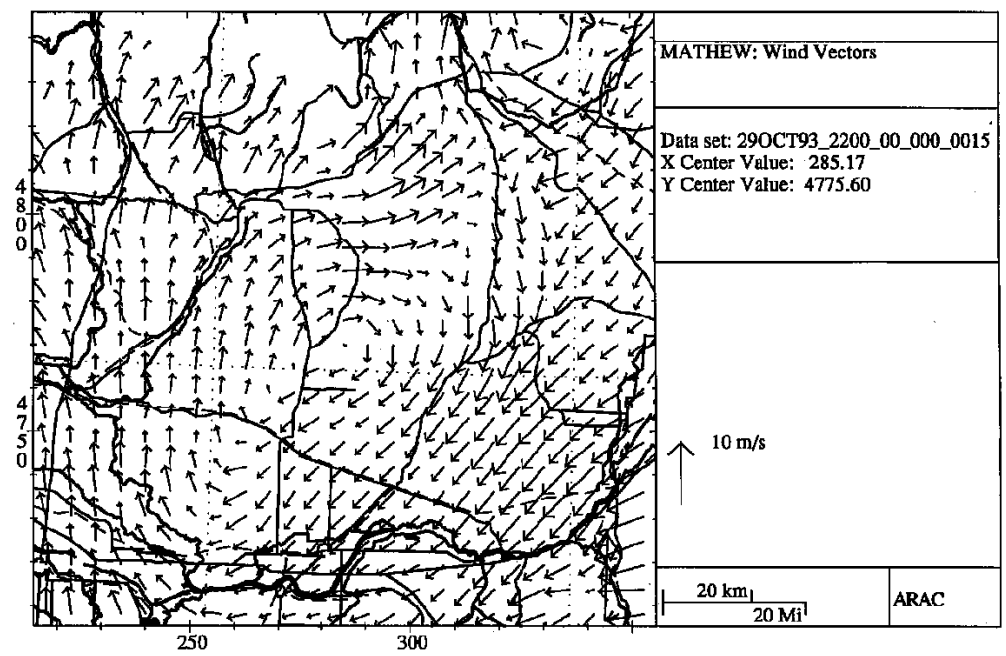

(c)

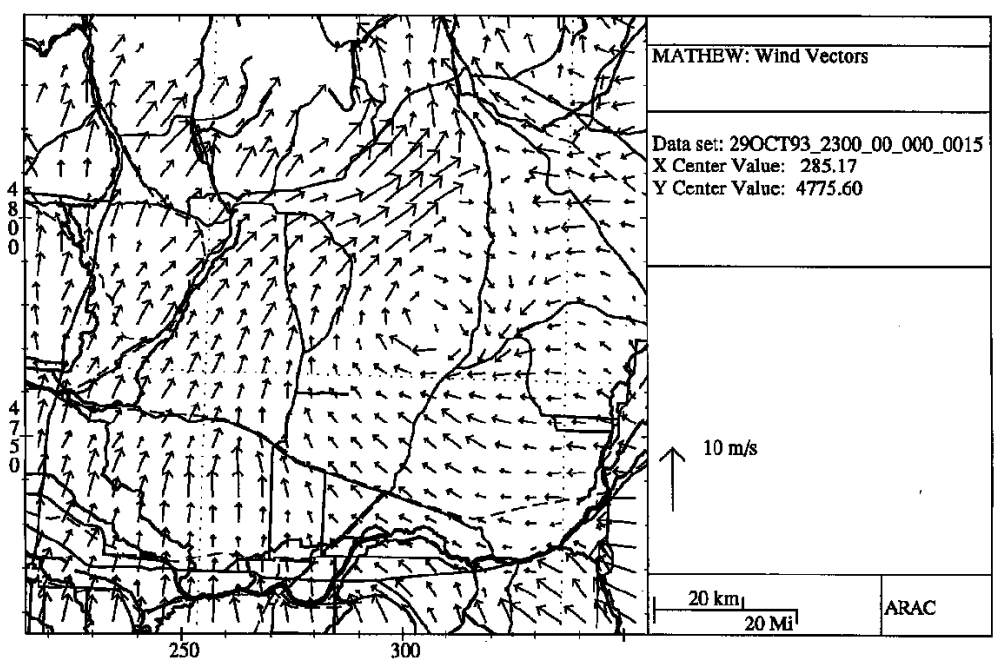

Figure 31. Modeled near-surface wind field for Release \#3 at (a) 2100 UTC, (b) 2200 UTC, and (c) 2300 UTC. 
illustrates an area criss-crossed by the aircraft several times from about 1705 to 1730 UTC. During this time the modeled $10 \mathrm{ppt}$ contour progressed westward across this region beginning at about 1700 UTC and reaching the western end at about 1730 UTC. Finally, region D contains measurement data taken between about 1745 and 1830 UTC. Model calculations also agree with these measurement hits. However region D shows the approximate western and southern extent of the modeled plume which missed the measurement hits indicated in areas $\mathrm{E}$ and $\mathrm{F}$, also taken during this same time period.

\section{Particulate Releases}

Two particulates, methyl salicylate (MeS) and triethyl phosphate (TEPO), were simultaneously released with the SF6 tracer. Because of the small size of these particulates (in the 5 micron range), their calculated transport and diffusion contour patterns are not significantly different from the SF6 patterns previously described. It would therefore be reasonable to expect these particulates to be approximately colocated with the SF6 tracer for at least the first few hours during the experimental periods.

However, as reported in Corey (1994), measurements did not show a consistent detection pattern. One identified concern is that, although the aircraft was often successful in measuring both the SF6 and particulate plume, truck-based measurements often recorded little or no particulate and did not seem well correlated with the truck's surface SF6 measurements. There seems to be little reason to expect any sort of meteorological or transport differences to produce this anomaly in surface data, although changing wind direction as a function height could in some cases explain differences in plume location depending on altitude.

Corey (1994) offers several possible contributing factors for the inconsistent measurement results (e.g. high humidity, presence of NOx, etc.). Another factor, which complicates a thorough analysis, is the relative scarcity of pertinent truck-based measurements. In Table 3 of Corey (1994) SF6, MeS, and TEPO measurements are summarized. Based on the test logs and flight path information, ARAC staff have identified only five surface measurements which were approximately co-located in latitude, longitude and time with the aircraft during the Release 1-4 flight periods summarized in this Table. In most of these cases the measurement locations are relatively close to the calculated plume boundary (i.e. in areas of high concentration gradients), and all have model-predicted MeS and TEPO concentrations of less than $10 \mathrm{ppt}$.

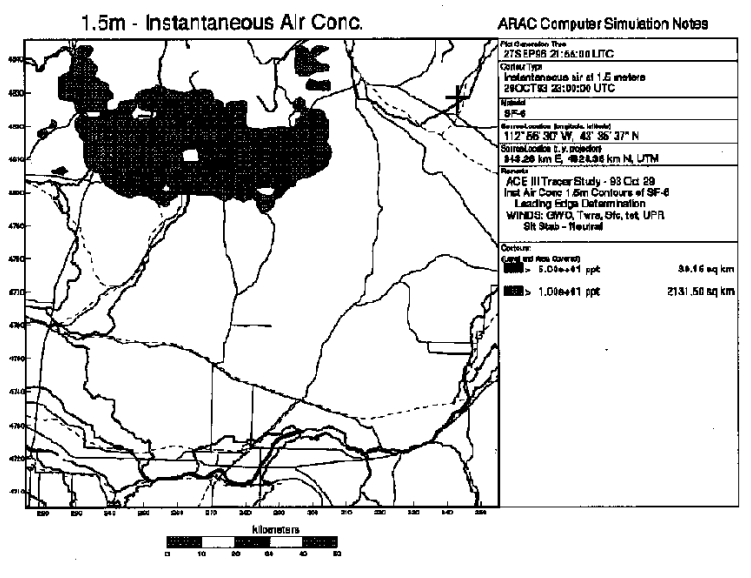

Figure 32. Modeled SF6 surface air concentrations (in ppt) for Release \#3 at 2300 UTC. 
(a)

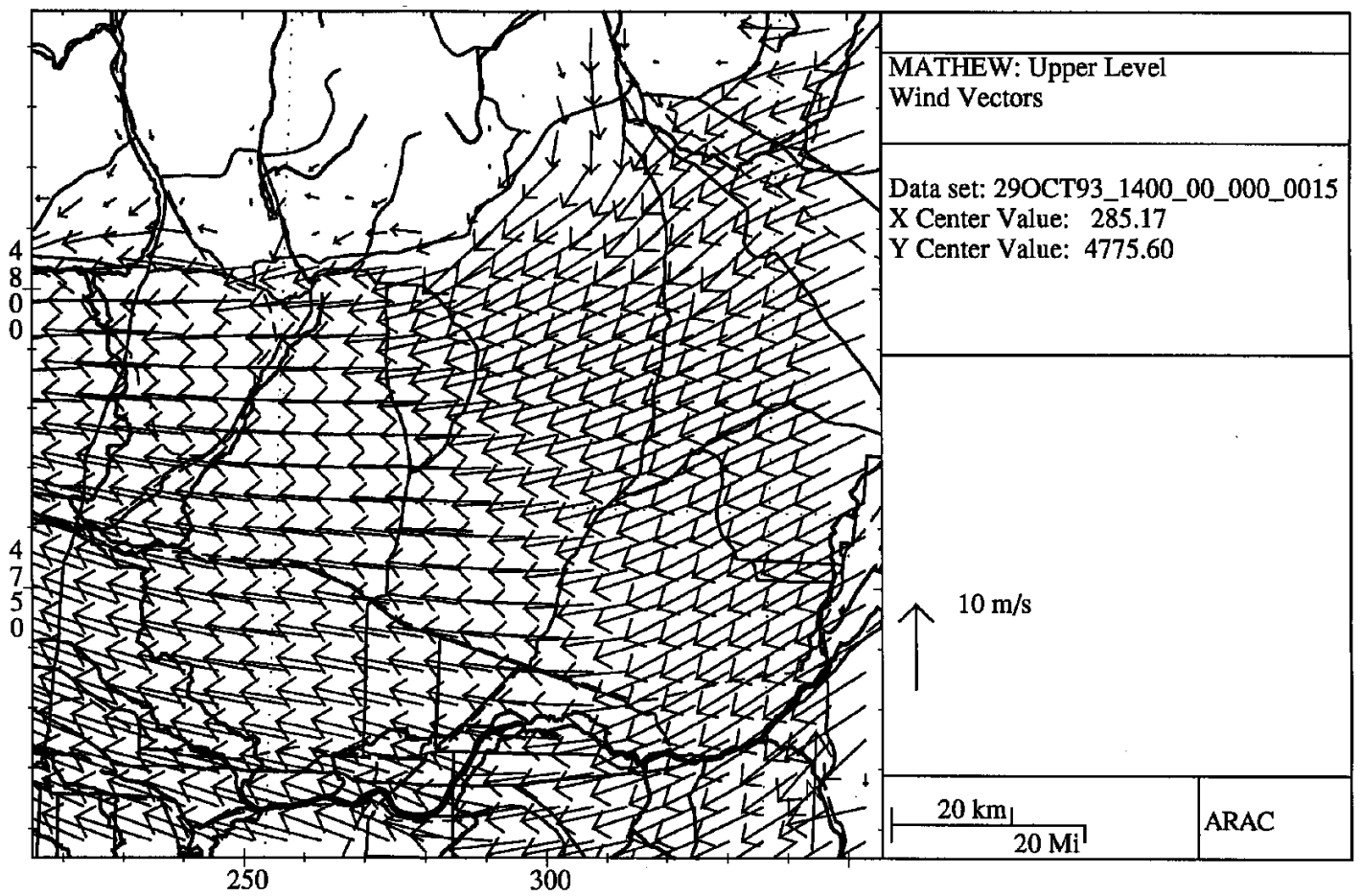

(b)

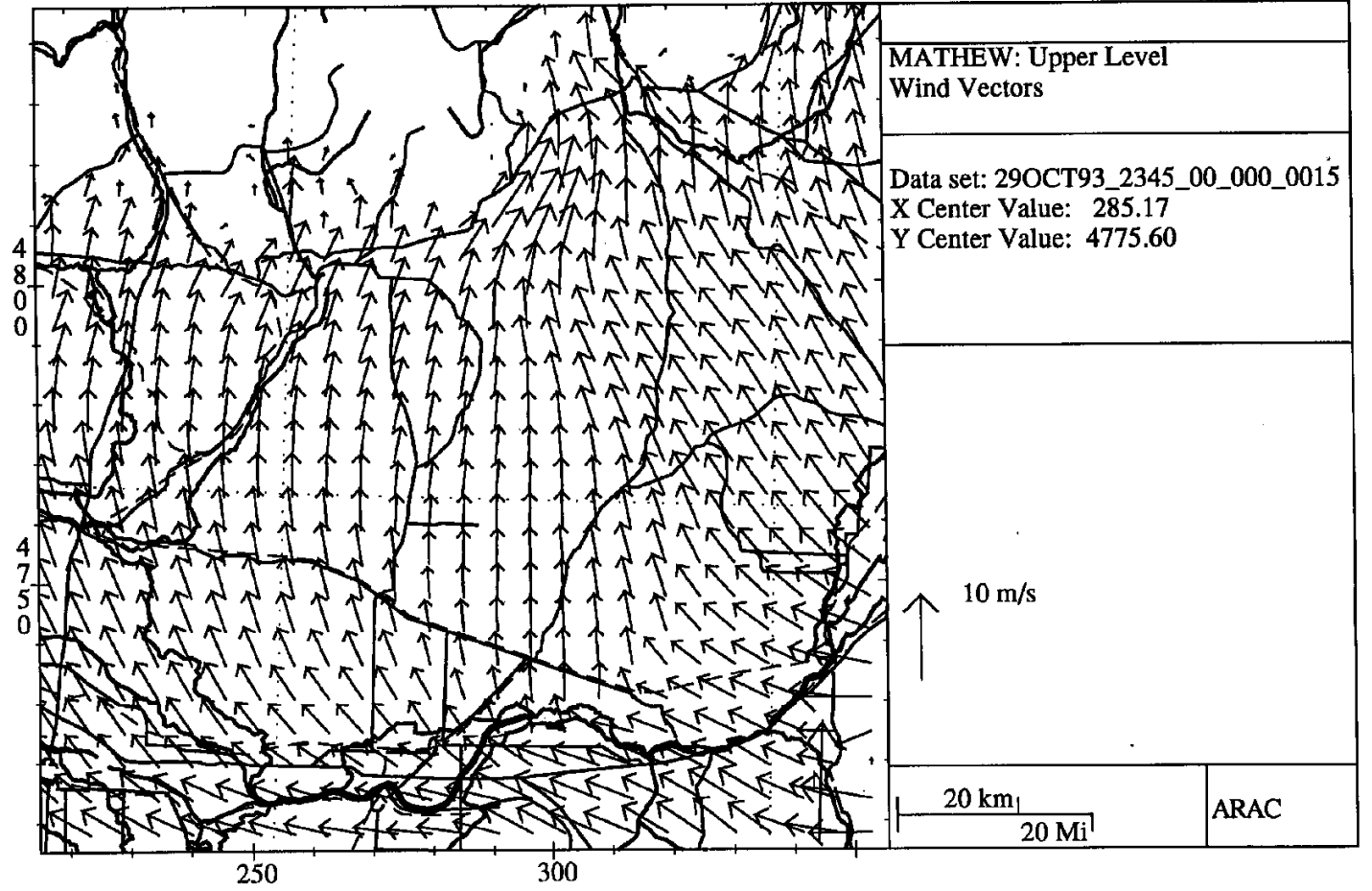

Figure 33. Modeled wind field 800 meters above the surface for Release \#3 at (a) 1400 UTC, and (b) 2345 UTC. 


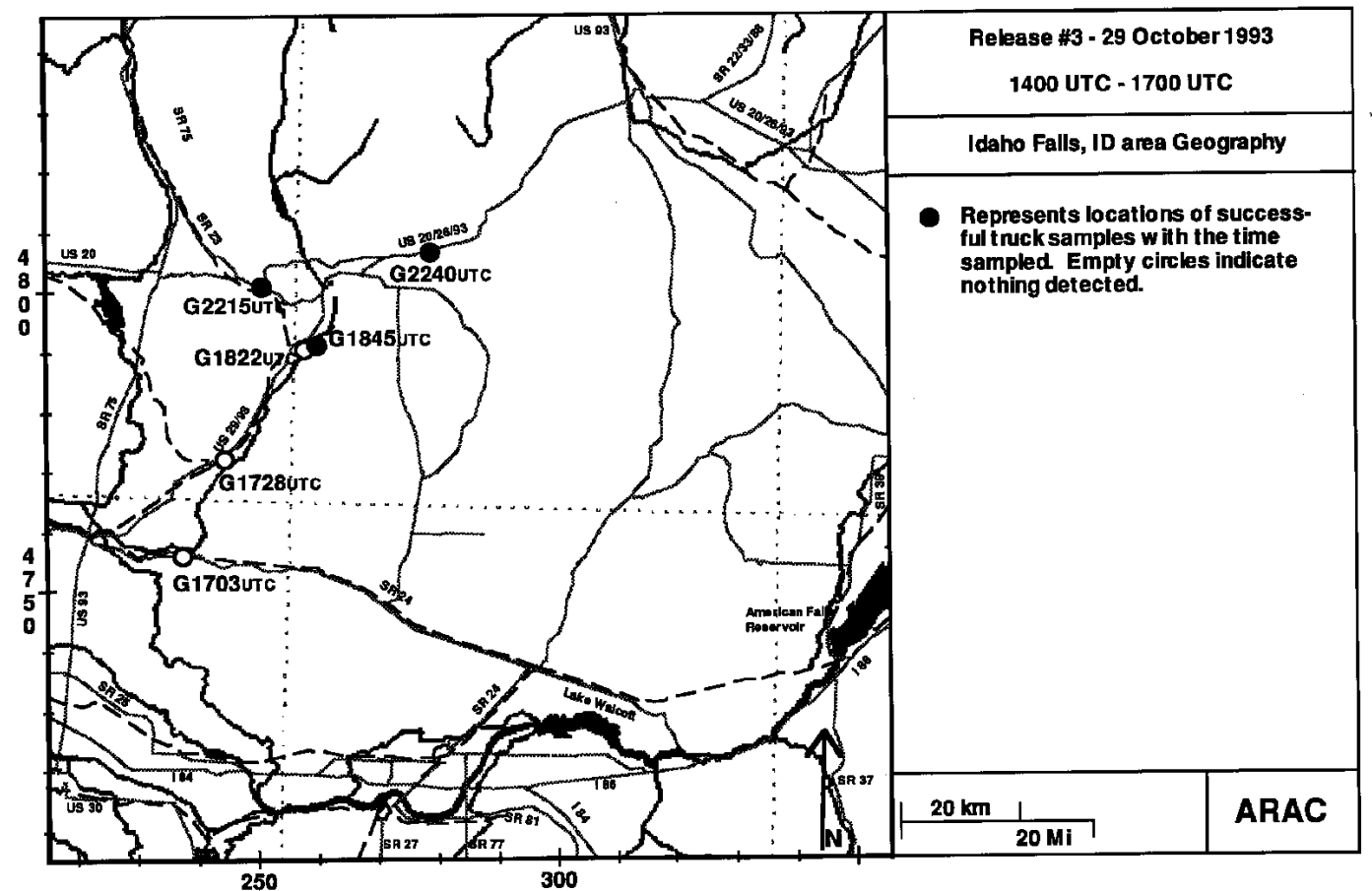

Figure 34. SF6 surface measurements for Release \#3. Solid circles indicate locations of plume "hits" (e.g. measurement of at least $10 \mathrm{ppt}$ ). Empty circles indicate locations of plume "misses" (e.g. measurement less than $10 \mathrm{ppt}$ ). The times of the measurements are indicated for each location.

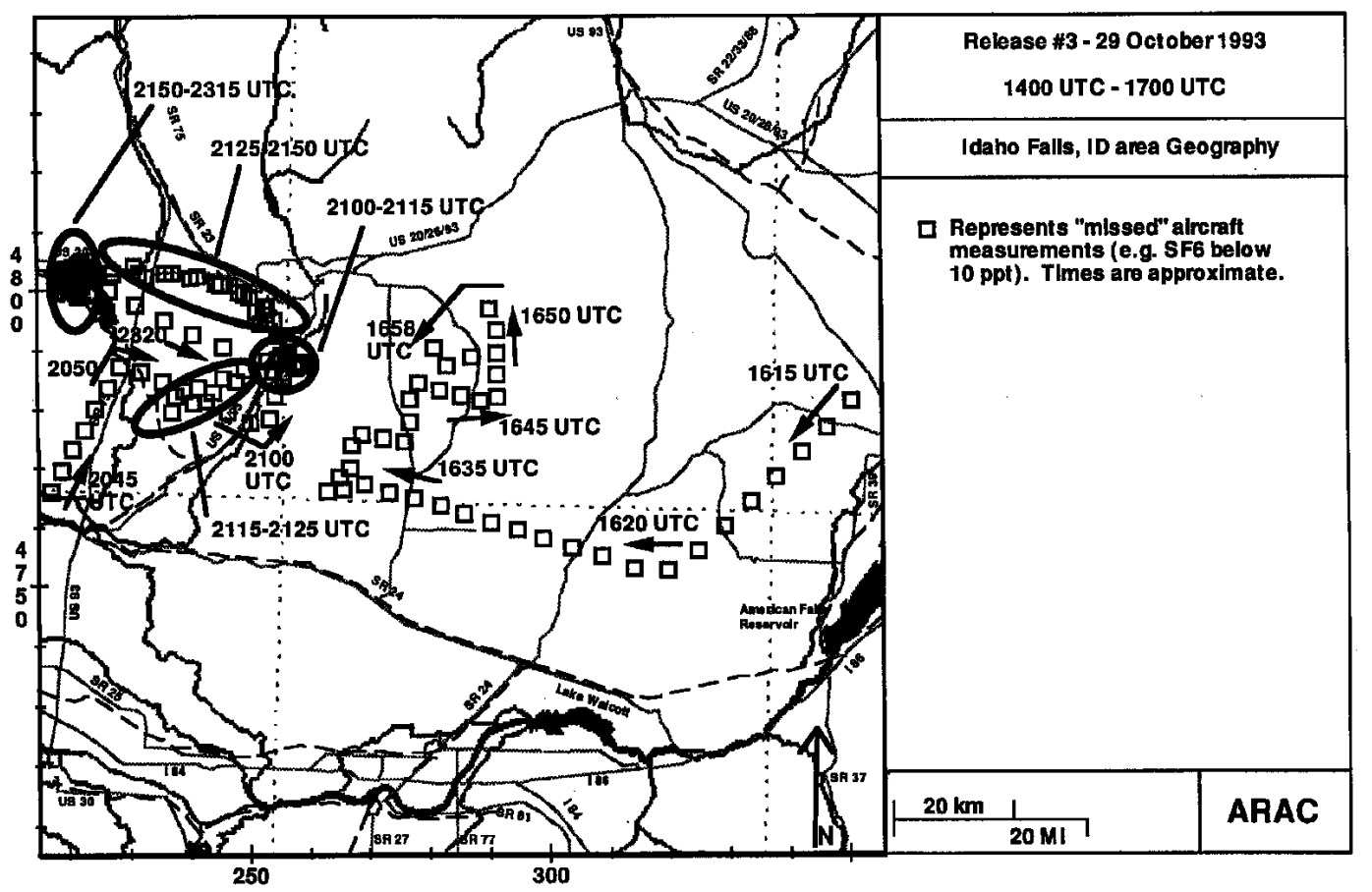

Figure 35. SF6 aircraft plume "misses" (measurements less than $10 \mathrm{ppt}$ ) for Release \#3. The approximate times of the measurements are indicated. 
Lacking the specific MeS and TEPO measurements as a function of time and location, ARAC staff compared the available SF6 truck and aircraft measurement data (limited to only those times when both platforms recorded samples) with model calculations in an attempt to reconcile data shown in Table 3 of Corey (1994) and to further examine perceived incongruities between the truck and aircraft data. These time periods typically extend beyond those listed in Corey (1994). These comparisons are summarized in the next few sub-sections.

\section{Release 1}

During the first release aircraft samples were taken over the truck measurement locations during the period of about 2145 to 2215 UTC. The pertinent truck measurements are those taken at 2146 and 2207 UTC shown in Figure 11. The test's $\log$ quotes these truck locations as marking the northern and eastern boundaries of the plume, respectively (i.e. the locations of the minimum detectable SF6 concentration, 10 ppt). This matches the modeled 2200 UTC 10 ppt contour, shown in Figure 7 extremely well (although the model places the western plume boundary at the 2146 UTC truck location instead of the northern boundary). Since MeS and TEPO release rates were approximately one-half of the SF6 release, we would expect surface particulate measurements to be about 4-5 ppt, which is predicted by modeled calculations. This seems to match the SIM mode truck concentrations of 5 and $2 \mathrm{ppt}$ shown in Corey's Table 3 rather well. It seems reasonable to expect that the SCAN mode should have indicated the presence of the particulate at at least one of these sample locations as long as the instrumentation can measure concentrations less than 10 ppt. (It is unclear however exactly which truck measurements are included in the Table's values, as the flight period listed in the Table is 2215-2355 UTC during which time no truck data was actually recorded.)

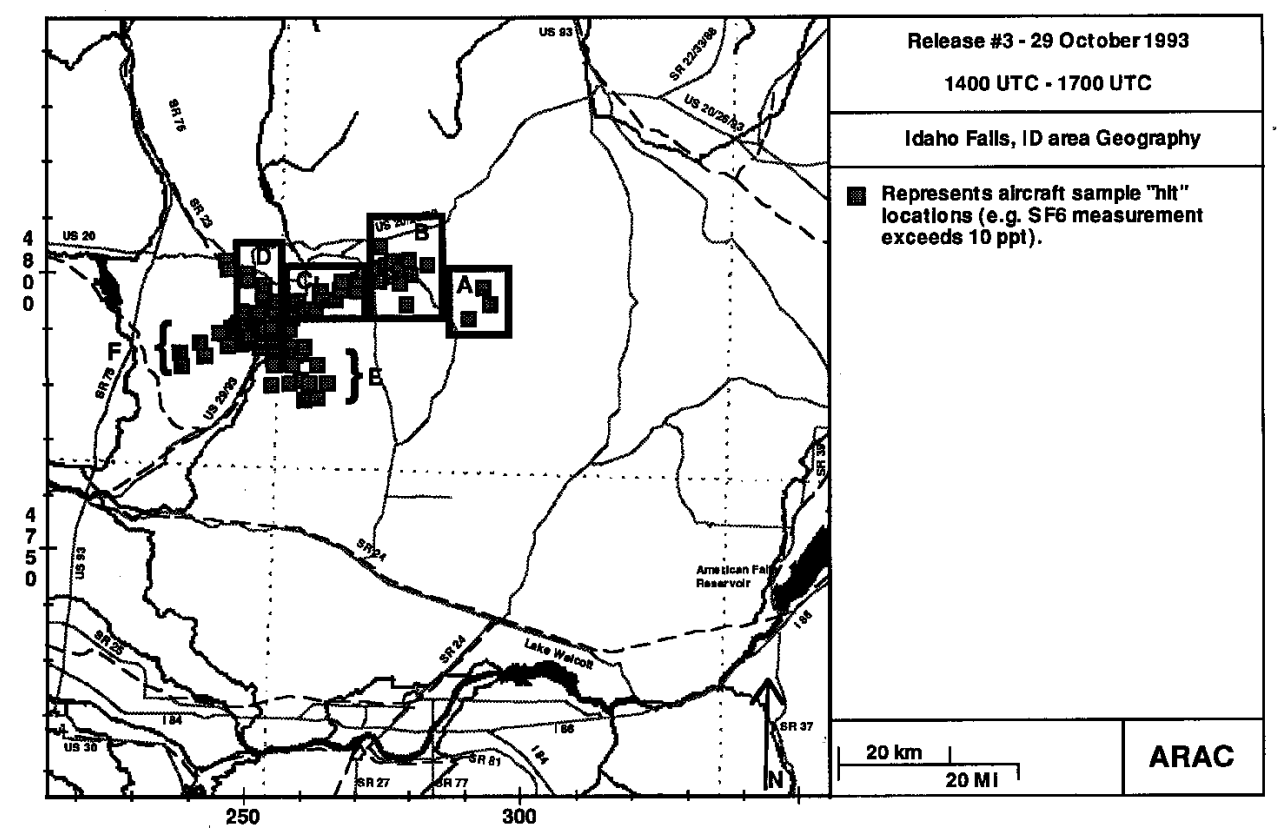

Figure 36. SF6 aircraft plume "hits" (measurements of at least $10 \mathrm{ppt}$ ) for Release \#3. 
Between the periods of 2140-2150 UTC and 2205-2215 UTC (covering the two truck measurement times), the aircraft was making repeated north/south running paths through the western half of area A shown in Figure 13. During these flight paths the aircraft SF6 samples range from about 40-180 ppt as it criss-crossed the plume. This range is consistent with the modeled concentrations at the approximate flight altitude (500 meters) shown by the calculated 2200 UTC contours in Figure 37. Note that the elevated plume is predicted to be slightly more to the east than the surface plume. We would expect the particulate concentrations for this portion of the flight to be on the order of about one-half of the SF6 concentrations, however these data are not available for comparison.

\section{Release 2}

During the second release there were two truck measurements taken during the aircraft flight periods. These are the 2015 and 2028 UTC measurements shown in Figure 24. Unfortunately during this time period the aircraft was sampling approximately 30 kilometers to the southwest of the truck locations, so consistent latitude/longitude surface and elevated plume measurements are not available.

It appears from Corey (1994) that both particulates were measured in both the truck SCAN and SIM modes (apparently the only release in which the truck SCAN mode detected the particulates). It is interesting to note that although the magnitude of the modeled particulate calculations fall between the 4 and $2 \mathrm{ppt}$ SIM mode truck measurements and the 24 and 90 ppt SCAN mode measurements, these modeled particulate concentrations are unexpectedly $75-85 \%$ (instead of about $50 \%$ ) less than the modeled SF6 surface concentrations at these truck locations. Since these measurements were taken almost 8 hours after the beginning of the release, some effects of the particle settling and deposition (with an average fall of around 25 meters during this time for 5 micron particles) may be leading to slight differences in the modeled gas and particulate plumes. The wind shear mentioned earlier in the discussion of the wind flow patterns would aid the possible divergence of the two plumes. However it is difficult to believe that this factor alone would produce the measured differences between the SF6 and particulate plumes reported in Corey (1994).

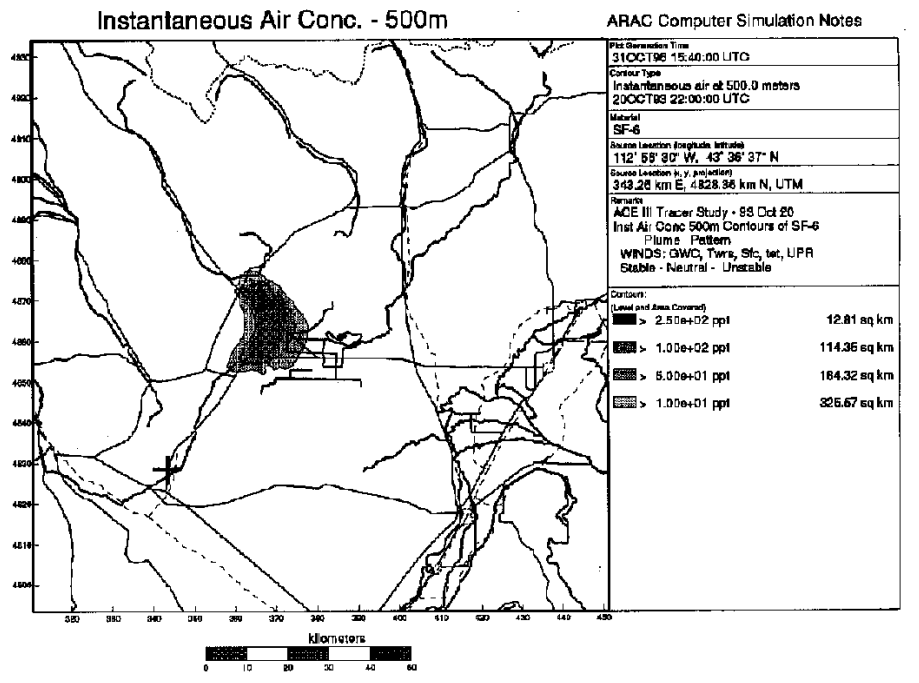

Figure 37. Modeled SF6 air concentrations (in ppt) for Release \#1 at 500 meters above the surface at 2200 UTC. Contours are 250, 100, 50 and 10 ppt. 


\section{Release 3}

As was the case in the first release, the aircraft flight path during the third release was over the approximate truck location for about one-half hour, during which time the truck completed 2 samples. These samples are those shown in Figure 34 and were taken at 1822 and 1845 UTC. Also, as in the first release, the model calculations agree very well with the truck measurements, being consistent with an SF6 concentration of less than $10 \mathrm{ppt}$ at the 1822 UTC location and with the measured concentration of $30 \mathrm{ppt}$ at the 1845 UTC location. Model calculations also indicate average particulate concentrations at these times to be in the 1-10 ppt range, once again agreeing with the SIM mode measurements listed in Table 3 of Cory (1994). However, again as with the first release, the failure of the truck SCAN mode to detect the particulates seems inconsistent with the model results (even though the measurement locations are relatively close to the modeled plume edges).

During this time the aircraft was taking measurements a few kilometers to the south at about 200 meters above the surface. The flight path was in the approximate location of the model calculated 10 ppt SF6 contour marking the southern extent of the measurable plume. Aircraft measurements however were on the order of 130-170 ppt, indicating that the model positioned the elevated plume too far northward at this time. While the elevated measurements of about 5 times that of the surface can well be explained by possible wind shear or other meteorological processes, no evidence of such processes is evident in the limited available data, and therefore their potential effects are not predicted by the model. We might expect therefore that the modeled particulate concentrations of around a few ppt predicted for the aircraft path are in fact too low. Again however, no data for this time period are available for comparison.

\section{Release 4}

As mentioned earlier, Schalk (1996) discusses release 4 in detail. During this release the aircraft was approximately over the truck location for only a single measurement (at 1719 UTC). As Schalk (1996) shows, the modeled plume failed to move far enough to the east to reflect either the 25 ppt SF6 truck measurement or corresponding aircraft measurements. The truck sample is however consistent with the SF6 "hot spots" apparently being measured at that time by the aircraft a few kilometers to the east, which recorded concentrations of 17 and 44 ppt interspersed with several plume misses (e.g. concentrations less than $10 \mathrm{ppt}$ ).

The model, of course, also predicts that no particulates were in the area. Corey (1994) however does not supply relative aircraft and truck particulate concentrations, as was done for some of the other releases. The spotty aircraft SF6 measurements (at 200 meters above the surface) again suggest that the measurements were taken near the plume boundary where regions of high concentration gradients are prevalent.

\section{$\underline{\text { Summary }}$}

ARAC staff have applied transport and diffusion models to releases $1-4$ of the ACE field trials. The wind flow patterns as a function of time and comparison of model results with surface and elevated SF6 measurements are described here for releases 1-3, while release 4 is described in detail in Schalk (1996).

Summaries of measurements of two particulate tracers, co-released with the SF6, are presented in Corey (1994). Experiment managers are concerned with apparent incongruities between the relative SF6 and particulate concentration measurements taken by aircraft versus truck instrumentation. The complete particulate data set was not available for reference. 
Analysis of model results focused on the reproducibility of measurements given in Table 3 of Corey (1994). Only time periods when the aircraft was sampling over the corresponding truck locations were considered. The analysis was hampered by the scarcity of instances when this occurred ( 5 in all), and by the lack of data reported which were isolated to only these short periods.

In general it is expected that the particulate and SF6 tracer plumes would be approximately co-located, so that significant differences between their sampled concentrations (not attributable to a difference in their source term) usually cannot be explained from model calculations. However, it should be recognized that the model calculations indicate some of the truck measurements were taken relatively close to the plume boundary where concentration gradients are relatively large, and where small differences in plume transport could magnify concentration differences. Also, although the aircraft flight paths were approximately over the 5 selected truck measurement locations, the paths sometimes tended to take the aircraft across the modeled plume which would expose the sampler to higher concentrations than were measured by the truck near the plume boundary. There is little support in the limited available meteorological data to expect a surface released plume to become elevated and not to mix uniformly throughout the boundary layer during the time period of the experiment.

\section{$\underline{\text { References }}$}

Corey, Thomas D., Analysis of the Atmospheric Collection Equipment (ACE) III Air Sampling Test Results (DRAFT), Air Force Technical Applications Center, 25 July 1994

Schalk, Walter W., Modeling SF6 Plume Dispersion in Complex Terrain and
Meteorology with a Limited Data Set, Lawrence Livermore National Laboratory, UCRL-ID-125646, October 1996

This work was performed under the auspices of the U.S. Department of Energy at Lawrence Livermore National Laboratory under contract number W7405-Eng-48. 


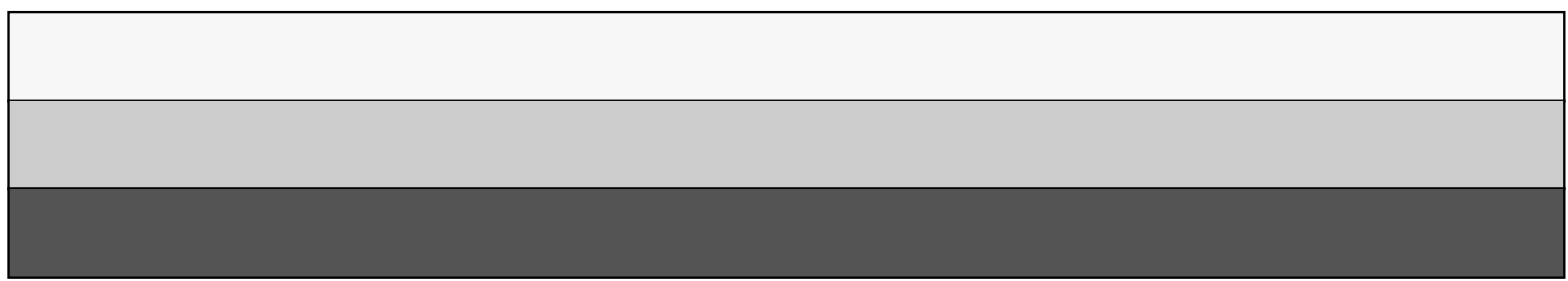

